\title{
Hydrological response in the Danube lower basin to some internal and external climate forcing factors
}

\author{
Ileana Mares ${ }^{1}$, Venera Dobrica ${ }^{1}$, Crisan Demetrescu ${ }^{1}$, Constantin Mares $^{2}$ \\ ${ }^{1}$ Institute of Geodynamics, Romanian Academy, Bucharest, Romania \\ ${ }^{2}$ National Institute of Hydrology and Water Management, Bucharest, Romania
}

\begin{abstract}
Of the internal factors, we tested the predictors from the fields of precipitation, temperature, pressure and geopotential at $500 \mathrm{hPa}$. From the external factors, we considered the indices of solar/geomagnetic activity. Our analysis was achieved separately for each season, for two time periods 1901-2000 and 1948-2000.

We applied developments in empirical orthogonal functions (EOFs), cross correlations, power spectra, filters, composite maps. In analysis of the correlative results, we took into account, the serial correlation of time series.

For the atmospheric variables simultaneously, the most significant results (confidence levels of 95\%) are related to the predictors, considering the difference between standardized temperatures and precipitation (TPP), except for winter season, when the best predictors are the first principal component ( $\mathrm{PC} 1$ ) of the precipitation field and the Greenland-BalkanOscillation index (GBOI). The GBOI is better predictor for precipitation, in comparison with North Atlantic Oscillation index (NAOI) for the middle and lower Danube basin.

The significant results, with the confidence level more than $95 \%$, were obtained for the PC1-precipitation and TPP during winter/spring, which can be considered good predictors for spring/summer discharge in the Danube lower basin.

Simultaneous, the significant signal of geomagnetic index (aa), was obtained for the smoothed data by band pass filter. For the different lags, the atmospheric variables respond to solar/geomagnetic activity after about 2-3 years. The external signals in the terrestrial variables are revealed also by power spectra and composite maps. The power spectra for the terrestrial variables show significant peaks that can be associated with the interannual variability, Quasi-Biennial Oscillation influence and solar/geomagnetic signals.

The filtering procedures led to improvement of the correlative analyses between solar or geomagnetic activity and terrestrial variables, under the condition of a rigorous test of the statistical significance.
\end{abstract}

Keywords: NAO, GBOI, serial correlation, low and band pass filter, atmospheric blocking, Danube basin, climate changes

\section{Introduction}

Climatic system is a closed system, being influenced mainly by external factors, whose action is modulated by the internal mechanisms. Therefore, it is difficult to assess climatic system response to various external factors, the discrimination action of each is sometimes even impossible. The main external factors as is known are: solar activity in its various forms and the greenhouse gases that cause climate variability. The quantifying the 
Hydrol. Earth Syst. Sci. Discuss., doi:10.5194/hess-2016-304, 2016

Manuscript under review for journal Hydrol. Earth Syst. Sci.

Published: 28 June 2016

(c) Author(s) 2016. CC-BY 3.0 License.

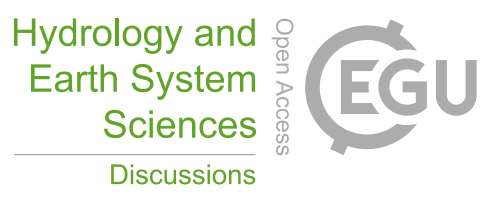

48 impact of each factor on the climate system is subject to various uncertainties. As shown in

49 Cubasch et al. (1997), as well as in Benestad and Schmidt (2009) is difficult to distinguish

50 between anthropogenic signal and the solar forcing in the climate change, especially if we

51 wanted to assess if the greenhouse or the solar forcing could be responsible for the recent

52 warming. An explanation of this shortcoming is related to the limits of simulation climate

53 models and lack of long data on many parts of the Earth, to estimate the impact of solar

54 activity.

In Brugnara et al. (2013) are reviewed recent studies on the impact of solar activity / geomagnetic on the climate. After a statistical reconstruction of the main atmospheric fields for more than 250 years, the authors performed an analysis of the solar signal of 11 years in different terrestrial datasets, and they found that there was a robust response of the tropospheric late-wintertime circulation to the sunspot cycle, independently from the date set. This response is particularly significant over Europe.

There were many preoccupations regarding the impact of greenhouse gases, resulting from climate modeling under various scenarios, on the water regime of the Danube. We mention only some of these studies. In Mares et al. $(2011,2012)$ were processed climate variables obtained from four global models of climate change: CNRM, ECHAM5, EGMAM and IPSL, under A1B scenario. It was found for Danube lower basin, that the probability to have extreme events (hydrological drought and great discharges) increases in the second half of the $21^{\text {st }}$ century comparing to the first half. A more complex methodology for postprocessing of outputs of climate models is found in Papadimitriou et al. (2016), where an analysis of the changes in future drought climatology was performed for five major European basins (including Danube) and the impact global warming was estimated.

Regarding internal factors that influence climate at regional or local scale, best known index is related to the North Atlantic Oscillation (NAO). After Hurrell et al. (2003), NAO is an internal variability mode of the atmosphere that depends exclusively on the dipolar pressure distribution.

For the south - eastern European zone, only NAO is not a good enough predictor for Danube discharge. Rimbu et al. (2002) showed that there is an out-of-phase relationship between the time series of the Danube river discharge anomalies and the NAO index. Also, Rimbu et al. (2005) was found that spring Danube discharge anomalies are significantly related to winter Sea Surface Temperature (SST) anomalies. In Mares et al. (2002) was found that NAO signal in climate events in the Danube lower basin is relatively weak, in comparison with other regions.

However, we must note that NAO is a very good predictor for some regions. Thus, for example NAOI is a significant predictor for : Seine river (Massey et al., 2010; El - Janyani et al., 2012), northeastern Algeria (Turki, et al., 2016), southern Sweden (Drobyshev et al., 2011), the northern Italy (Zanchettin et al., 2008).

The recent research (Valty et al., 2015) warns that for the predictor's selection such as $\mathrm{NAO}$, need to consider the dynamics of the total oceanic and hydrological system over wider areas. In fact all climate system needs to be considered. In Hertig et al. (2015) are described the mechanisms underlying the non-linearity and non-stationarity of the climate system components, with a focus on NAO and the consequences of climate non-stationarities are discussed.

In the present study, in comparison with the NAO influence on climate variables in the Danube basin, we analysed the atmospheric index Greenland-Balkan-Oscillation (GBO), which reflect the baric contrast between the Balkan zone and the Greenland zone. The GBO index was introduced first time in Mares et al. (2013b) and in the present study it is shown in detail, the GBOI informativity in comparison with NAOI, for the Danube basin. 
Hydrol. Earth Syst. Sci. Discuss., doi:10.5194/hess-2016-304, 2016

Manuscript under review for journal Hydrol. Earth Syst. Sci.

Published: 28 June 2016

(c) Author(s) 2016. CC-BY 3.0 License.

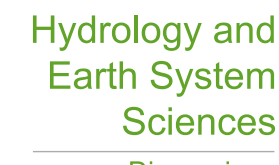

Discussions

Taking into account that solar activity plays an essential role in modulating the blocking parameters with the strongest signal in the Atlantic sector (Barriopedro et al., 2008; Rimbu and Lohmann, 2011), in the present paper we consider also, the indices of atmospheric circulation of blocking type.

In this paper, except for the highlighting the atmospheric circulation of blocking type taking into account the Quasi-Biennial Oscillation (QBO) phases and solar minimum or maximum (number Wolf), we did not investigate any further interaction between internal and external factors. This interaction was developed in other papers such as Van Loon and Meehl (2014).

The main aim of our work was to select predictors from the terrestrial and solar /geomagnetic variables with a significant informativity for predictand, i.e. discharge in the Danube lower basin. We obtained this informativity by applying robust tests for the statistical significance. Because the solar and geomagnetic variables, as well as the smoothing procedures through various filters, respectively low pass filter and band pass filters applied in this investigation, shows strong serial correlations, all correlative analyzes were performed through rigorous testing of statistical significance. The number of observations was reduced to the effective number of degrees of freedom, corresponding to the independent observations.

This paper is organized as follows: Sect. 2 shows data processed at regional scale (2.1) and large scale (2.2), as well as the indices that define solar and geomagnetic activity (2.3).

In Section 3, we describe the methodology used. There are many investigations related to solar / geomagnetic signal in the Earth's climate, some of them use smoothing of data, both related to solar activity and the terrestrial variables. This smoothing induces a high serial correlation, which produces very high correlations between time series analysis. Some authors investigating these signals in the terrestrial variables take into account these large serial correlations induced by these smoothing, others do not. Therefore in Sect. 3 we focused on testing the statistical significance of solar / geomagnetic signal in climate variables, taking into account the high autocorrelation induced by the smoothing processes. The confidence level is found by robust method. We also briefly described the procedure of testing of confidence levels of the peaks of the power spctra.

Section 4 contains the results and their discussion. Concerning the link between atmospheric circulation at the large scale and the climate variables at local or regional scales and described in 4.1, we demonstrated that GBOI is a predictor more significant than NAOI for the climate variables in the Danube middle and lower basin. In 4.2, for the period 19012000, we considered several predictors depending on climatic variables in the Danube basin, as well the indices of large-scale atmospheric circulation and we tested predictor's weight for the discharge in the lower basin. In subsection 4.3, are presented the results obtained from the analysis of solar/geomagnetic signal simultaneously with the terrestrial variables (4.3.1) and with some lags (4.3.2) and QBO role in modulating these signals (4.3.3). The conclusions are presented in the Sect.5.

\section{Data}

\section{1 Regional scale}

Since the Danube discharge estimation has great importance for the economic sector of Romania, in the present investigation we focused on predictors for Danube lower basin discharge. The lower basin Danube discharge was evidenced by Orsova station (Q_ORS), located at the entrance of the Danube in Romania and representing an integrator of the upper and middle basin. Our analysis was achieved separately for each season, for the two time 
Hydrol. Earth Syst. Sci. Discuss., doi:10.5194/hess-2016-304, 2016

Manuscript under review for journal Hydrol. Earth Syst. Sci.

Published: 28 June 2016

(c) Author(s) 2016. CC-BY 3.0 License.

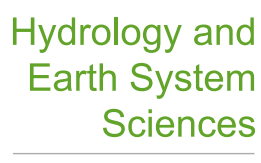

Discussions
147

148

149

150

151

152

153

154

155

156

157

158

159

160

161

162

163

164

165

166

167

168

169

170

171

172

173

174

175

176

177

178

179

180

181

182

183

184

185

186

187

188

189

190

191

192

193

194

195

196

periods 1901-2000 and 1948-2000. For the period 1901-2000, in the Danube upper and middle basin (DUMB), were considered fields of precipitation (PP), mean temperature (T), diurnal temperature range (DTR), maximum and minimum temperatures (Tmx, Tmn), cloud cover (CLD) at 15 meteorological stations upstream of Orsova. The selection of stations was done according to their position on the Danube or on the tributaries of the river (Fig.1). The values of monthly precipitation and temperature (CRU TS3.10.01) accessing (http://climexp.knmi.nl). Data-sets are calculated on high-resolution $(0.5 \times 0.5$ degree $)$ grids by Climatic Research Unit (CRU), and we selected for each station (with the respective coordinators) the option "half grid points".

The stations position in relation to Orsova is given in Figure 1. For each station was calculated a simple drought index (TPPI), which is calculated by the difference between standardized temperatures and precipitation. All analyses were achieved using the seasonal averages for all variables considered in this study.

\subsection{Large scale}

In order to see the influence of large-scale atmospheric circulation on the variables at the regional scale, we considered the seasonal mean values of sea level pressure field (SLP) on the sector $\left(50^{\circ} \mathrm{W}-40^{\circ} \mathrm{E}, 30^{\circ}-65^{\circ} \mathrm{N}\right)$. We had to extract SLP data from the National Center for Atmospheric Research (NCAR), (http://rda.ucar.edu/datasets/ds010.1). As mentioned in the associated documentation, this dataset contains the longest continuous time series of monthly girded Northern Hemisphere sea-level pressure data in the DSS archive. The 5degree latitude/longitude grids, computed from the daily grids, begin in 1899 and cover the Northern Hemisphere from $15^{\circ} \mathrm{N}$ to the North Pole. The accuracy and quality of this data is discussed in Trenberth and Paolino (1980).

We found a new index started from tests achieved using correlative analysis between the first principal component (PC1) of the Empirical Orthogonal Functions (EOFs) development of the precipitation field defined at 15 stations from Danube basin and each grid point where SLP is defined. By determining the centers of inverse correlation nuclei (positive and negative) and by considering the normalized differences between SLP at Nuuk and Novi Sad (Fig.2), we obtained this index, which we called Greenland-Balkan-Oscillation index (GBOI). This index was introduced by Mares et al. (2013b) and tested in the previous works of the authors (Mares et al., 2014a, 2015a,b, Mares et al., 2016a,b).

The NAOI were download from http://www.ldeo.columbia.edu/res/pi/NAO/

For 1948-2000 period beside of variables taken over 1901-2000, we considered and blocking type indices.

For the geopotential at $500 \mathrm{hPa}$ (1948-2000) provided by British Atmospheric Data Centre $(B A D C)$ three sectors were taken into account: Atlantic-European $(\mathrm{AE})$ on the domain $\left(50^{\circ} \mathrm{W}-40^{\circ} \mathrm{E} ; 35^{\circ} \mathrm{N}-65^{\circ} \mathrm{N}\right)$, Atlantic $(\mathrm{A})$ defined in $\left(50^{\circ} \mathrm{W}-0^{\circ}, 35^{\circ} \mathrm{N}-65^{\circ} \mathrm{N}\right)$ and European (E) in the region $\left(0^{\circ}-40^{\circ} \mathrm{E} ; 35^{\circ} \mathrm{N}-65^{\circ} \mathrm{N}\right)$.

\subsection{Solar / geomagnetic data}

For this 100 year period the solar/geomagnetic activities were quantified by Wolf number and $a a$ index. For the period 1948-2000, solar forcing is quantified by the $10.7 \mathrm{~cm}$ solar flux instead of Wolf number. Since the $10.7 \mathrm{~cm}$ flux is a more objective measurement, and always measured on the same instruments, this proxy "sunspot number" should have a similar behaviour but smaller intrinsic scatter than the true sunspot number (ftp://ftp.ngdc.noaa.gov/STP/SOLAR_DATA/). The values for the Quasi-Biennial Oscillation 
Hydrol. Earth Syst. Sci. Discuss., doi:10.5194/hess-2016-304, 2016

Manuscript under review for journal Hydrol. Earth Syst. Sci.

Published: 28 June 2016

(c) Author(s) 2016. CC-BY 3.0 License.

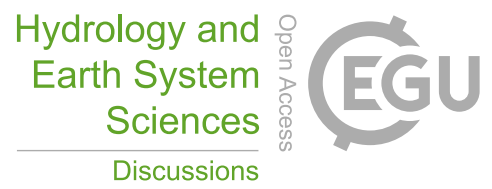

(QBO) were downloaded from Free University of Berlin (http://www.geo.fuberlin.de/met/ag/strat/produkte/qbo/qbo.dat).

\section{Methodology}

The time series of the variables considered in the 15 stations were filtered by the first principal component (PC1) of empirical orthogonal functions (EOFs) development.

The analyse of the low frequency components of the atmosphere, based on decomposition in multivariate EOF (MEOF), was used by the authors of the present paper in Mares et al. (2009, 2015, 2016a, b).

The $500 \mathrm{hPa}$ geopotential field was filtered by blocking index $\left(\mathrm{I}_{\mathrm{B}}\right)$ as is described in Lejenas and Okland (1983). Such a blocking event can be identified when the averaged zonal index computed as the $500-\mathrm{hPa}$ height difference between $40^{\circ}$ and $60^{\circ} \mathrm{N}$, is negative over $30^{\circ}$ in longitude. Taking into account the above definition, in the present study, we calculated for each longitude $\lambda$, three indices for the regions: Atlantic-European (AEBI), Atlantic (ABI) and Europe (EBI) after the formula:

$I B(\lambda)=\Phi(\lambda, 57.50 N)-\Phi(\lambda, 37.50 N)$

where $\Phi$ is the $500 \mathrm{hPa}$ geopotential field, and blocking index $I_{B}$ is a mean for $\lambda$ longitudes of IB $(\lambda)$. In our case IB positive reflects a blocking type circulation.

In the preprocessing analyses, low and band pass filters were applied.

Low pass filters were applied to eliminate oscillations due to other factors as El Niño-Southern Oscillation (ENSO) than the possible influence of solar/ geomagnetic activities. The Mann filter (Mann, 2004, 2008) was applied with three variants that eliminate frequencies corresponding the periods lower than 8,10 and 20 years.

Besides the low pass filters specified above, which was applied only to the terrestrial fields, the band pass filters were applied both to the terrestrial and solar or geomagnetic variables. The band pass filters were of the Butterworth type, and the variables have been filtered in the 4-8, 9-15 and 17-28 years bands.

In Lohmann et al. (2004) the solar variations associated with the Schwabe, Hale, and Gleissberg cycles were detected in the spatial patterns in sea-surface temperature and sealevel pressure, using band pass filters with frequencies appropriate to each of the solar cycles. Significant correlations between global surface air temperature and solar activity were obtained by Echer et al. (2009), applying wavelet decomposition with different the band frequencies.

As is known in the literature, the response of climate variables to the solar/geomagnetic activity is evidenced not only simultaneously but also certain differences, we performed cross - correlation with a lag of 5 years. Explanation of the physical mechanism of correlations with certain lags between solar activity and climate variables is found in Gray et al. (2013) and Scaife et al. (2013).

In order to find the significance level of the correlation coefficient, we have to take into account the fact that by the smoothing both terrestrial and solar/ geomagnetic variables present a serial correlation. In this case, we have to estimate the equivalent sample size (ESS). There are more methods to find the correlations statistical significance among the series pairs presenting serial correlations. A part of these methods are present in Thiebaux and Zwiers (1984), Zwiers and Storch (1995), Ebisuzaki (1997).

In Mares et al. (2013a), the procedure described by Zwiers and Storch (1995) for ESS estimation was applied in order to estimate the statistical significance of the climatic signal in sea level pressure field (SLP) in $21^{\text {st }}$ century in comparison with 20-th century. 
In the present analysis, in order to find the ESS, namely the number of effectively independent observations $\left(\mathrm{N}_{\mathrm{eff}}\right)$ is applied a simple formula, which is appropriate for the correlations involving smoothed data (Bretherton et al., 1999).

$$
N_{e f f}=N \frac{\left(1-r_{1} r_{2}\right)}{\left(1+r_{1} r_{2}\right)}
$$

where $r_{1}$ and $r_{2}$ are the lag-1 autocorrelation coefficients corresponding to the two time series correlated and $\mathrm{N}$ number of the observations.

In the next phase, the t-statistic is used to test the statistical significance of the correlation coefficient:

$$
t=|r|\left[\left(N_{e f f}-2\right) /\left(1-r^{2}\right)\right]^{1 / 2}
$$

In equation (3), $r$ is the correlation coefficient between the two variables and $N_{\text {eff }}$ is effective number used in the testing procedure.

According to von Storch and Zwiers (1999), the null hypothesis $r=0$, is tested by comparing the $t$ value in equation (3) with the critical values of $\mathrm{t}$ distribution with $n_{e}-2$ degrees of freedom.

The correlated time series must have a Gaussian distribution. For this reason in the present study we have also applied and the nonparametric Kendall correlation coefficient, which measures of correlation of the ranked data. Applying the algorithm described in Press et al. (1992), correlation values and corresponding significance p-levels are obtained. A comparison between the Pearson and Kendall correlation coefficients is found in Love et al. (2011), where the statistical significance between sunspots, geomagnetic activity and global temperature, is tested.

Among the statistical methods that might be used to test solar or geomagnetic activity signal in the climatic variables, in this study we will take into account also on testing the statistical significance of the amplitude of the power spectra in time series. Testing the statistical significance of the peaks obtained from an analysis of a time series by power spectra is usually done by building a reference spectrum (background) and comparing the amplitude spectrum analyzed time series based spectrum amplitudes. This spectrum is a series based on white noise or most often a red noise series (Ghil et al. 2002, Torrence and Campo, 1998). At first all amplitudes above the background noise amplitudes are considered significant. But to test how significant are these peaks are testing their statistical significance compared with different levels of significance desired.

A significance test requires null hypothesis significance. For spectral analysis, the null hypothesis is that the time series has no significant peak and spectral estimation differs from the noise spectrum (background). Rejection of the null hypothesis means accepting peaks of the spectrum series of observations that exceed a certain level of significance. As shown in Mann and Less (1996) theoretical justifications exist for considering red noise as noise reference (background) for climate and hydrological time series.

The power spectra achieved in this study were estimated by multitaper method (MTM) (Thomson, 1982, Ghil et al., 2002, Mann and Less (1996)). The MTM procedure is a nonparametric technique that does not require a priori a model for the generation of time series analysis, while harmonic spectral analysis assumes that the data generation process include components purely periodic and white noise which are overlapped (Ghil et al., 2002).

In Mares et al. (2016), more practical details were given on estimating background noise and significance of power spectra peaks, for the applications refering to the influence of the Palmer drought indices in the Danube discharge. 
Hydrol. Earth Syst. Sci. Discuss., doi:10.5194/hess-2016-304, 2016

Manuscript under review for journal Hydrol. Earth Syst. Sci.

Published: 28 June 2016

(c) Author(s) 2016. CC-BY 3.0 License.

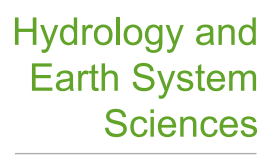

Discussions

7

\section{Results and discussions}

\subsection{Connection between atmospheric circulation at the large scale and climate events at regional or local scale}

The atmospheric circulation at the large scale is quantified in this paragraph by North Atlantic Oscillation index (NAOI), Greenland Balkan Oscillation Index (GBOI) and indices that highlight the blocking type circulation. The direct impact of NAO is less obvious than GBO impact for the surrounding areas of the lower Danube basin as revealed in this study and in previous investigations (Mares et al., 2013b, 2014, 2015a,b 2016a,b).

The high correlations between GBOI and precipitation are stable over time (Table 1). From how GBO and NAO indices are defined, they have opposite signs. Temporal evolution for winter of the first principal component (PC1) for the precipitation in the Danube basin in comparison with GBOI values is given in Fig.3.

The details on the stations are given in Fig.4, where are presented the correlation coefficients between winter precipitation at 15 stations and NAOI and GBOI for two periods 1916-1957 and 1958-1999. From this figure, it is clear that the GBOI signal is stronger than NAO signal, except for the first stations located in the upper basin of the Danube.

Since the Danube discharge estimation in spring season with some anticipation has great importance for the economic sector of Romania, the best predictors at the large scale for Orsova discharge in spring, with one season anticipation (winter) were revealed, with high confidence level (> 99\%): GBOI as well as the atmospheric circulation of blocking type, quantified by European blocking index (EBI). The Figure 5 shows spring Orsova discharge (standardized) in comparison with European blocking index $(\mathrm{R}=-0.54)$ and GBOI $(\mathrm{R}=0.53)$ for winter in the period 1948-2000. The opposite signs of the Orsova discharge correlations with EBI and GBOI are due to the definitions of the two indices. The negative correlations between discharge and EBI can be explained as follows. As shown in Davini et al. (2012), the midlatitude traditional blocking localized over Europe, uniformly present in a band ranging from the Azores up to Scandinavia, leads to a relatively high pressure field in most of Europe. This field of high pressure, which defines a positive blocking index, and is not favorable for precipitation,leads to in low discharge of the Danube at Orsova. A positive correlation coefficient between the Danube discharge at Orsova and GBOI, means that a positive GBO index lead to a low pressure in the Danube basin area and therefore a high discharge.

The role of the atmospheric circulation of blocking type on events in the Danube Basin is described in many papers, including Mares et al. (2006), Blöschl et al. (2013).

\subsection{Testing predictor variables for estimating the discharge in the Danube lower basin (1901-2000)}

To underline the contribution of the nine predictors, defined at the 15 stations in the Danube basin, described in Section 2, we represented in Figure 6 the correlation coefficients between Danube discharge at Orsova (lower basin) and these predictors for each of the four seasons. PC1 in Fig. 6 represents the first principal component of EOFs development of the respective fields. If we take into account the confidence level at $99 \%$, of correlation coefficients for 100 values, it should exceed 0.254 . There are many predictors that are statistically significant at this level of confidence, but we take into consideration only those having the highest correlation coefficients. As can be seen from Figure 6, the greatest contribution to the Danube discharge in seasons of spring, summer and fall, brings the drought index (depending on precipitation and average temperature), with the correlation 
Hydrol. Earth Syst. Sci. Discuss., doi:10.5194/hess-2016-304, 2016

Manuscript under review for journal Hydrol. Earth Syst. Sci.

Published: 28 June 2016

(c) Author(s) 2016. CC-BY 3.0 License.

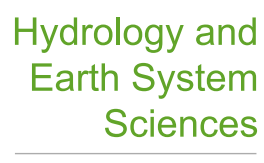

Discussions

coefficients (r) of $-0.450-0.730$ for spring and summer and respectively -0.700 for fall. In winter season, the highest contribution to the discharge in lower Danube basin, it has precipitation field in the upper and middle basin $(r=0.500)$, followed by GBOI $(r=0.430)$. Also, it is revealed that for the spring season, where contribution drought index TPPI is lower than in summer and autumn season, the GBOI and DTR can be considered good predictors with $\mathrm{r}=0.420$ and respectively -0.417 .

Regarding consideration of the predictors with some anticipation to the Danube discharge, the significant results obtained with an anticipation of a season, are presented in the Fig. 7. For spring, the best predictor is clearly drought index (TPPI), taken in winter $(r=-$ $0.62)$, and also for summer discharge, TPPI in spring is a significant predictor $(\mathrm{r}=-0.55)$, but quite closely related this is the spring precipitation field quantified by PC1 $(\mathrm{r}=-0.53)$.

The results obtained in this study are consistent with those of Mares et al. (2016a), where that the Palmer drought indices were found good predictors for the discharge in lower basin.

\subsection{Solar/geomagnetic signal in the climate fields in Danube basin}

Solar activity was represented by Wolf numbers for the period 1901-2000 and by 10.7$\mathrm{cm}$ solar flux for the period 1948-2000. Although the solar flux is closely correlated with Wolf numbers, these values are not identical, the correlation coefficient varying with the season (0.98-0.99). The geomagnetic activity was quantified by $a a$ index for the two periods analyzed (1901-2000 and 1948-2000). Regarding the link between solar activity and geomagnetic, details are found in Demetrescu and Dobrica (2008).

Solar/geomagnetic signal was tested by: correlative analyses (simultaneous and cross correlation), composite maps and spectral analyses. Before correlative analysis, data were filtered using low and band pass filters for the terrestrial variables and only band pass filters for the solar / geomagnetic indices.

Related to the low pass filter, the Mann filter (Mann, 2004, 2008) was applied with three variants that eliminate frequencies corresponding the periods lower than 8,10 and 20 years. The analysis revealed that from the three variants, time series cutoff 8 , responded best to variations in solar / geomagnetic activities.

In many investigations, significant solar signal in the terrestrial variables, have been obtained applying band pass filters, for isolating the frequency bands of interest (Lohmann et al., 2004, Dima et al, 2005, Prestes et al. 2011, Echer et al. 2012, Wang and Zhao, 2012).

In the present study we apply a band pass filter with the three frequency bands: (4$8 \mathrm{yr}),(9-15 \mathrm{yr})$ and $(17-28 \mathrm{yr})$. Because after the filtering process, the time series show a strong autocorrelation, to test the statistical significance of the link between the terrestrial and solar variables, we use the t-test, which takes into account the effective number of independent variables and the correlation coefficient between two series. The effective number is determined in function of the serial correlations of the two series analyzed. Details are given in Section 2. The most significant results were obtained for the filtered terrestrial variables, taken with some lags related to solar or geomagnetic activity.

\subsubsection{Simultaneously signal}

The Table 2 presents some of the results that have a confidence level higher or least of $95 \%$, which worth to be taken into account for the analysis period of 100 years (1901-2000). Here are presented only the results simultaneously for three categories of data: non-filtered (UF), smoothed by low pass filter (LPF), eliminating, the periods less than or equal to 8 years, 
Hydrol. Earth Syst. Sci. Discuss., doi:10.5194/hess-2016-304, 2016

Manuscript under review for journal Hydrol. Earth Syst. Sci.

Published: 28 June 2016

(c) Author(s) 2016. CC-BY 3.0 License.

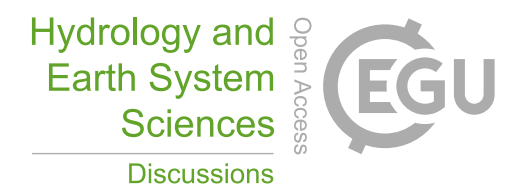

395 only for terrestrial variables, and band pass filter (BPF) applied for both time series (terrestrial

396

397

398

399

400

401

402

403

404

405

406

407

408

409

410

411

412

413 and solar / geomagnetic indices).

Since not all variables have a normal distribution, the Kendall's coefficient was associated Pearson's coefficient. The nonparametric Kendall coefficient is valid for time series that do not have a normal distribution. There are cases when the difference between the two correlation coefficients is relatively high and this difference may be due to statistical distribution that deviates from normal.

As can be seen from Table 2, smoothing time series lead to improved correlation coefficients, the most significant results were obtained by band-pass filter with frequency corresponding to 9-15 yr. Also, tests were achieved and 17-28 yr, but although, highest correlation coefficients were obtained, it is difficult to take a decision, because the effective number is very small (about 5 years), due to serial correlation very high, caused by such filters. For such filtering are necessary much larger sets of data. An example is given in Tab. 2 to test the correlation between the GBOI and Wolf number during fall season.

The results presented in the Table 2 , related to the significant correlations indicated by Pearson coefficients $(r)$, are supported by Kendall correlation coefficients $(\tau)$, and their levels of significance $(p)$. Bold lines means there are at least two situations for the same season (filtered or unfiltered data) having a significantly CL.

As can be seen from Table 2, highest correlations with aa, were obtained during the summer season with $r=0.796$ for temperature and with $r=-0.721$ for precipitation, for a smoothing by a BPF with the band (9-15yr). Also, in summer, it is worth to mention the aa signal in drought index (TPPI) with the correlation is 0.787 , corresponding filtering with (9$15 \mathrm{yr}$ ). From the definition of this index, it reflects the behavior of both temperature and precipitation, but the sign is given by temperature. It can be noting that drought index TPPI, which is a combination of temperature and precipitation, responds better to signal $a a$, compared to PC1_PP. Therefore, a geomagnetic activity maximum (minimum) determines a situation of drought (wet) in the Danube basin during spring and summer.

Regarding solar activity signal in temperatures and precipitation, the highest correlation coefficients were found for the fall season (0.699) and respectively for spring ($0.538)$ in the band filter $(9-15 \mathrm{yr})$. From the Table 2, are observed correlations with the number Wolf, with a particularly high confidence level (>99\%) in the case of considering time series smoothed by the band (4-8 yr), as atmospheric circulation index GBOI (summer and winter).

The results obtained in the present investigation, referring to the temperature and precipitation variables are in accordance with the ones from Dobrica et al. $(2009,2012)$, where have been analysed the annually mean of long time series (100-150 years) for the temperature and precipitation records from 14 meteorological stations in Romania. There are some differences, because in this investigation, fields of temperature and precipitation are taken on another area, smoothing procedures are different and the analysis is done on each season separately. However, the correlations with the geomagnetic $a a$ index and Wolf numbers have the same sign, ie positive for temperatures and, negative for precipitation respectively.

Reducing the number of effective observations, when is applied a smoothing, is discussed in Palamara and Bryant (2004), where they test the statistical significance of the relationship between geomagnetic activity and the Northern Annular Mode.

Although the results obtained here by the BPF shows the largest correlation coefficients, however those obtained by BPF (9-15) must be analyzed together with results obtained by other filters. An example is the solar signal, quantified by Wolf number, in the drought index (TPPI), for which in the spring, unfiltered data, filtered by the low pass filter, and those by BPF (4-8 and 9-15) indicate correlations with confidence level higher than $90 \%$, 
Hydrol. Earth Syst. Sci. Discuss., doi:10.5194/hess-2016-304, 2016

Manuscript under review for journal Hydrol. Earth Syst. Sci.

Published: 28 June 2016

(c) Author(s) 2016. CC-BY 3.0 License.

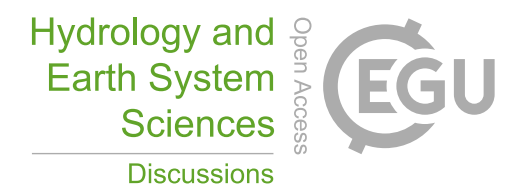

10

445 it means that significance of the correlation in this case, does not depend on the time series 446 size.

447 Taking into account both signals of the geomagnetic and solar activity, we can notice that during spring, TPPI has the best respond for unfiltered or filtered time series.

Considering the importance of the Danube discharge in our study, we analyze solar / geomagnetic signals in this variable. Thus, the $a a$ signal in Danube discharge at Orsova (Q_ORS), is seen as the most significant, during the summer season with correlation coefficient $r=-0.656$. But considering our criteria above enumerated, ie significant correlations in at least two cases, it is clear that we must focus on the discharge behavior in fall (Table 2), for which the smoothing by LPF and BPF (9-15) lead to the significant response to $a a$ impulse.

In the following, we present results obtained by analyzing the terrestrial and solar or geomagnetic data for the period 1948-2000. Although the time series are relatively short, was considered this period because some of the atmospheric variables, as indices that define the type blockage $500 \mathrm{hPa}$, are available only in 1948 . Also $10.7 \mathrm{~cm}$ solar flux that defines more clearly solar activity is just beginning in this period. In addition, we wanted to see if it improves the relationship between the terrestrial and solar indices, taking separately the years with positive or negative phase of Quasi-Biennial Oscillation (QBO).

In the Table 3 are presented the correlation coefficients, with a high confidence level (>95\%), obtained from the simultaneous correlative analyzes between terrestrial variables and gemagnetic ( aa), and solar activity (flux $10.7 \mathrm{~cm}$ ) indices on the other hand. It is observed that due to short time series, the smoothing by the band pass filter (9-15), although leads to the correlation coefficients with high confidence level, the number of degrees of freedom is quite small.

For this period of 53 years (1948-2000), the smoothing by BPF with the band (4-8 yr) appears most appropriate, especially for highlighting solar signal, where all three blocking indices considered in this paper, respond significantly to the solar impulse.

The solar or geomagnetic signals in the terrestrial variables can be emphasized also by the periodicities estimation by means of the power spectra. In the present study the power spectra were estimated by means of multitaper method (MTM). For the time series of unfiltered European blocking index (EBI) during winter, the power spectra given in the Fig.8a reveals that the most significant periodicity is related to QBO (2.4 years), and with an approximately $90 \%$ confidence level are the peaks at 10.7 and 14.2 years, which may be linked to 11-year solar/geomagnetic cycle. In Fig. 8b, which represents the power spectrum for EBI in the spring, the only significant peak with a confidence level of $95 \%$ is situated at 10 years. This is consistent with the results shown in Table 3, where during spring, the time series of blocking index EBI, both unfiltered and filtered by the band pass filter (4-8) have significant correlations with the aa geomagnetic index. Also, in winter (Fig. 8a), the EBI's response to solar activity, quantified by the Wolf number, is statistical significant with CL almost $99 \%$. If we take only spring season, the best significant peak related to QBO (Fig. 8c) is found in blocking index over Atlantic European region (AEBI).

Graphical representation of unfiltered time series was given to see whether the there are solar/ geomagnetic signals in the original series. The power spectra of the filtered series were not shown, because these series show peaks corresponding to the frequencies remaining after filtering procedure.

Regarding the period of 53 years (1948-2000), significant signals of the solar activity quantified by solar flux $10.7 \mathrm{~cm}$ were obtained for spring and summer in the Danube discharge at Orsova (Q_ORS), with different lags, especially to a delay of two years, where both unfiltered and filtered time series, indicate statistically significant correlations. 
Hydrol. Earth Syst. Sci. Discuss., doi:10.5194/hess-2016-304, 2016

Manuscript under review for journal Hydrol. Earth Syst. Sci.

Published: 28 June 2016

(c) Author(s) 2016. CC-BY 3.0 License.

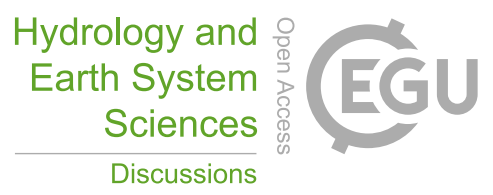

Like in the GBOI case, the discharge is inversely, but well correlated with solar activity. In Fig. 10a, correlation coefficients are shown at the lags 1-5 for three series, unfiltered (UF), smoothed by low pass filter (LPF) and the band pass filter (9-15). It can be observed that, if for the unfiltered data, the signal is significant at the lag 1 and 2, for the data smoothened by BPF, this signal is at the lags 2, 3 and 4. Taking into account the LPF result, can be considered the most significant result at the lag 2 years. In the Fig. 10b have been shown the coherent time evolutions of the solar flux and discharge, smoothed by BPF (9-15) with a lag of three years, where, the correlation coefficient is highest (-0. 769) and CL is 99\%.

From the above results, we can highlight that the Danube discharge in the lower basin, at the 2 or 3 years during spring and summer, after a maximum (minimum) solar, will be lower (higher).

A different response to solar activity was found in the time series of the index that defines a atmospheric circulation of blocking type over Atlantico-European region, for the period 1948-2000, during the winter season. As can be seen in Fig. 11, the response this index to the solar activity is significant with a delay of two years and three years compared to the solar flux. It is worth noting that in this case, the filtering process does not lead to an improvement of the significance of the correlation, even if its value increases. Thus it is necessary a rigorous test for correlation's significance, especially for data smoothed.

Therefore, we might conclude that about 2-3 years after producing a maximum (minimum) solar, winter, atmospheric circulation of blocking type is enhanced (weakened) over the Atlantico-European region.

\subsubsection{QBO role}

Regarding QBO influence on the relationship between solar activity and terrestrial parameters, there are several investigations (Van Loon and Labitzke, 1988; Bochníček et al.1999, Huth et al., 2009), which demonstrated that QBO phase is very important for emphasizing these links. We see in QBO mainly an important modulator of the impact of solar activity on the phenomena of the lower troposphere. To test these findings, in this paper, the years with east QBO phase, during winter months have been selected, and were made correlations between solar flux and more terrestrial variables. Winter, from the atmospheric indices of blocking type at $500 \mathrm{hPa}$, best response at the QBO signal, was found in the blocking over the European sector (EBI), with power spectrum shown in Fig. 8a. But the correlation coefficient between the solar flux and the unfiltered EBI during winter, for all those 53 years, is 0.15 and not is statistically significant. By selecting only the years with QBO in the east phase in the winter months (34 cases), the correlation coefficient is 0.32 at the confidence level around $95 \%$. It is interesting that although the power spectrum (Fig. 8a) highlights significant peaks related to the QBO (2.4 and 2.7ani), the correlation coefficient between EBI and QBO is insignificant. This suggests that the spectral representation is very useful in time series analysis and the QBO phases modulate the connection between solar activity and blocking circulation.

It is enlightening solar impact (by flux) on atmospheric circulation in the lower troposphere, during the east phase of QBO, when the solar maximum is associated with blocking event over the Northern Atlantic and north-western Europe (Fig. 12a), and a geopotential with a opposite distribution that occurs during the solar minimum. (Fig. 12b).

The advantage of the composite maps, used to outline the response to the solar signal, is shown in Sfîca et al. (2015), which specifies that through these composite maps, nonlinearities are taken into account, compared to using linear methods. 
Hydrol. Earth Syst. Sci. Discuss., doi:10.5194/hess-2016-304, 2016

Manuscript under review for journal Hydrol. Earth Syst. Sci.

Published: 28 June 2016

(c) Author(s) 2016. CC-BY 3.0 License.

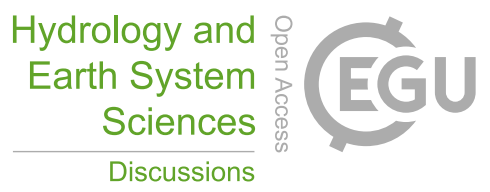

Our findings, presented in the Fig. 12, are in concordance with Barriopedro et al. (2008), namely, QBO is a modulator of the of the atmospheric circulation transformation from a blocking type circulation to a zonal one and vice versa, under the solar impact.

We mention that in the period 1948-2000 were recorded 34 months of winter (DJF) in which occurred east QBO phase and the solar flux has produced in the lower troposphere an atmospheric blocking events, or a zonal atmospheric circulation, at middle and higher latitudes, depending on the state of maximum or minimum solar activity, respectively.

\section{Conclusions}

In the present investigation, we focused on finding predictors for the discharge in the Danube lower basin, which present a high level of statistical significance.

In the first part of the paper we tested the predictors for the discharge, from the fields of temperature, precipitation, cloud cover in the Danube basin, and indices of atmospheric circulation over the European Atlantic region. For climate variables defined in the Danube basin, as predictor we used only the first principal component (PC1) of the EOFs decomposition and a drought index (TPPI) derived from the standardized temperature and precipitation.

The atmospheric circulation has been quantified by Greenland Balkan Oscillation (GBO) and North Atlantic Oscillation (NAO) indices and the blocking type indices. The analysis was performed separately for each season and on the two period (1901-2000) and (1948-2000).

Main statistically significant results for this part of our research are the following:

1. The correlative analyzes simultaneously for each season, revealed that, except for the winter season, drought index (TPPI) has the highest weight to the discharge variability in the lower basin of the Danube.

2. Testing the predictors, in order to see their predictive capacity, with a lag of several months in advance of discharge, concluded that TPPI in winter and spring is a good indicator for the Danube discharge in spring and summer respectively.

3. We demonstrated that for the winter, GBOI has an influence on the climate variables in the Danube middle and lower basin more significant than NAOI.

4. Analysis for the period 1948-2000, reveals that in winter, the GBOI weight for the Danube discharge is similar to those of the blocking index over the European sector.

In the second part of the paper, we focused on solar/geomagnetic signals in the terrestrial variables. Because the solar and geomagnetic variables as well as the smoothing procedures through various filters, respectively low pass filter and band pass filters applied in this investigation, shows strong serial correlations, all correlative analyzes were performed through rigorous testing of statistical significance. The number of observations was reduced to the effective number of degrees of freedom, corresponding to the independent observations. The filtering procedures led to improvement of the correlative analyses between solar or geomagnetic activity and terrestrial variables, under the condition of a rigorous test of the statistical significance.

The main findings of our research for this topic are the following:

5. The most significant signals of solar/geomagnetic activities were obtained in the drought indicator (TPPI). Because the precipitation does not respond just as well as, temperatures to the solar signal, is preferred analysis TPPI variable in stead of temperatures and precipitation separately.

6. From the analysis of correlations with the lags from 0 to five years delay of the terrestrial variables in comparison with the solar/geomagnetic activity, we obtained 
Hydrol. Earth Syst. Sci. Discuss., doi:10.5194/hess-2016-304, 2016

Manuscript under review for journal Hydrol. Earth Syst. Sci.

Published: 28 June 2016

(c) Author(s) 2016. CC-BY 3.0 License.

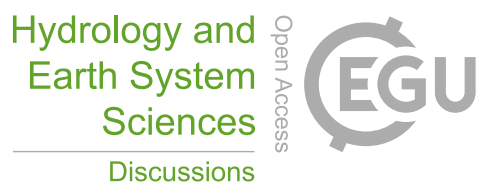

very different results, depending on the season and on the considered variables, as well as on the filtering procedure. Such, we might conclude that in winter, about 2-3 years after producing a maximum (minimum) solar, winter, atmospheric circulation of blocking type is enhanced (weakened) over the Atlantic-European region. Also, it was found that the Danube discharge in the lower basin, at the 2 or 3 years during spring and summer, after a maximum (minimum) solar, will be lower (higher).

7. A terrestrial variable that respond to the solar signal, even more significant than to the geomagnetic signal, is atmospheric circulation index GBO, in summer. Therefore, at the 2-3 years after a maximum (minimum) of solar activity, expects a response of atmospheric circulation in the Atlantic-European region, quantified by GBOI, by a diminution of this index, i.e. decrease (increase) of pressure in Greenland area and an increase (decrease) in atmospheric pressure in the Balkans.

8. By multitaper method (MTM) procedure, the power spectra have highlighted both quasi-periodicities related to solar activity and the other oscillations such as QBO. In the time series of AEBI (spring), and EBI (winter) the most significant periodicity is related to QBO (2.2-2.7 years) and with an approximately $90 \%$ confidence level there are peaks at 10-14 years, which may be linked to 11-year solar cycle.

9. The composite maps revealed that solar impact (by flux) on atmospheric circulation in the middle troposphere, during the east phase of QBO, is associated with blocking event over the Northen Atlantic and north-western Europe, and a geopotential with a opposite distribution that occurs during the solar minimum.

In this study, we focused only on observational data, so that in next our investigations, we will take into account significant predictors for the Danube basin found in this investigation, like GBOI, TPPI and atmospheric blocking indices from the outputs of the climate simulation models. Also we will take into account non-stationarities and non-linearities associated with the major modes of climate variability.

Acknowledgements. This study has been achieved under VALUE: COST Action ES1102.

\section{References}

Barriopedro, D., Garcia-Herrera, R., and Huth, R.: Solar modulation of Northern Hemisphere winter blocking, J. Geophys. Res., 113, D14118, doi:10.1029/2008JD009789, 2008.

Benestad, R.E.: Schmidt GA: Solar trends and global warming, J. Geophys. Res. 114:D14101, doi:10.1029/2008JD011639, 2009.

Blöschl, G., Nester, T., Komma, J., Parajka, J., and Perdigão, R. A. P.: The June 2013 flood in the Upper Danube Basin, and comparisons with the 2002, 1954 and 1899 floods, Hydrol. Earth Syst. Sci., 17, 5197-5212, doi:10.5194/hess-17-5197-2013, 2013.

Bochníček, J., Hejda, P., and Pýcha, J.: The effect of geomagnetic and solar activity on the distribution of controlling pressure formations in the Northern Hemisphere in winter, Studia geophysica et geodaetica, 43(4), 390-398,1999.

Bretherton, C.S., Widmann, M., Dymnikov, V.P., Wallace, J.M. and Bladé, I.: The effective number of spatial degrees of freedom of a time-varying field, Journal of climate, 12(7), 1990-2009, 1999.

Brugnara, Y., Brönnimann, S., Luterbacher, J., and Rozanov, E.: Influence of the sunspot cycle on the Northern Hemisphere wintertime circulation from long upper-air data sets, Atmos, Chem. Phys., 13, 6275-6288, doi:10.5194/acp-13-6275-2013, 2013.

Cubasch, U., Voss, R., Hegerl, G.C., Waszkewitz, J. and Crowley, T.J.: Simulation of the influence of solar radiation variations on the global climate with an ocean-atmosphere general circulation model, Climate Dynamics, 13(11), 757-767, 1997. 
Hydrol. Earth Syst. Sci. Discuss., doi:10.5194/hess-2016-304, 2016

Manuscript under review for journal Hydrol. Earth Syst. Sci.

Published: 28 June 2016

(c) Author(s) 2016. CC-BY 3.0 License.

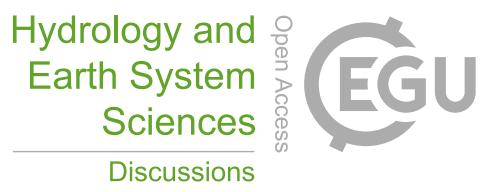

14

644

645

646

647

648

649

650

651

652

653

654

655

656

657

658

659

660

661

662

663

664

665

666

667

668

669

670

671

672

673

674

675

676

677

678

679

680

681

682

683

684

685

686

687

688

689

690

691

692
Davini, P., Cagnazzo, C. Gualdi, S. and Navarra, A.: Bidimensional Diagnostics, Variability, and Trends of Northern Hemisphere Blocking, J. Climate, 25, 6496-6509, 2012.

Demetrescu, C. and Dobrica,V.: Signature of Hale and Gleissberg solar cycles in the geomagnetic activity, J. Geophys. Res., 113, A02103, doi:10.1029/2007JA012570, 2008.

Dima, M., Lohmann, G. and Dima I.: Solar-Induced And Internal Climate Variability at decadal time scales, Int. J. Climatol., 25: 713-733, 2005.

Dobrica, V., C. Demetrescu, Boroneant, C. and Maris G.: Solar and geomagnetic activity effects on climate at regional and global scales: Case study-Romania, J.Atmos. Sol.-Terr. Phy., 71 (17-18), 1727-1735, doi:10.1016/j.jastp.2008.03.022, 2009.

Dobrica V, Demetrescu, C.: On the evolution of precipitation in Central and South-Eastern Europe and its relationship with Lower Danube discharge, in: AGU Fall Meeting Abstracts, 1 1, 1030, 2012.

Drobyshev, I., Niklasson, M., Linderholm, H.W., Seftigen, K., Hickler, T., Eggertsson, O.: Reconstruction of a regional drought index in southern Sweden since AD 1750, The Holocene 21(4) 667-679, doi: 10.1177/0959683610391312, 2011.

Ebisuzaki, W.: A Method to Estimate the Statistical Significance of a Correlation when the Data is Serially Correlated, J. Climate, 10:2147-2153, 1997.

Echer, M. S., Echer, E., Nordemann, D. J. R., and Rigozo, N. R.: Multi-resolution analysis of global surface air temperature and solar activity relationship, Journal of Atmospheric and Solar-Terrestrial Physics, 71(1), 41-44, 2009.

Echer, M.S., Echer, E., Rigozo, N.R., Brum, C.G.M., Nordemann, D.J.R., and Gonzalez, W.D.: On the relationship between global, hemispheric and latitudinal averaged air surface temperature (GISS time series) and solar activity, Journal of Atmospheric and SolarTerrestrial Physics, 74, pp.87-9,2012.

El-Janyani, S., Massei, N., Dupont, J.P., Fournier, M. and Dörfliger, N.: Hydrological responses of the chalk aquifer to the regional climatic signal, Journal of Hydrology, 464, 485-493, 2012.

Ghil, M., Allen, M.R., Dettinger, M.D., Ide, K., Kondrashov, D., Mann, M.E., Robertson, A.W., Saunders, A., Tian, Y., Varadi, F., Yiou, P.: Advanced spectral methods for climatic time series, Reviews of Geophysics 40 (1), doi: 10.1029/2001RG000092, 2002.

Gray, L. J., A. A. Scaife, D. M. Mitchell, S. Osprey, S. Ineson, S. Hardiman, N. Butchart, J. Knight, R. Sutton,and Kodera K.: A lagged response to the 11 year solar cycle in observed winter Atlantic/Euro pean weather patterns, J. Geophys. Res. Atmos., 118, 13, 405-13, 420, doi:10.1002/2013JD020062, 2013.

Hertig, E., Beck,C., Wanner,H., Jacobeit, J.: A review of non-stationarities in climate variability of the last century with focus on the North Atlantic-European sector, EarthScience Reviews 147, 1-17, doi:10.1016/j.earscirev.2015.04.009, 2015.

Hurrell, JW, Kushnir Y, Visbeck M, Ottersen G.: Research Abstracts EGU2007-A-08910 9:1029- 2003. An overview of the North Atlantic Oscillation. In: Hurrell, J.W., Kushnir, Y., Ottersen, G., Visbeck, M. (Eds.), The North Atlantic Oscillation, Climatic Significance and Environmental Impact, AGU Geophysical Monograph, 134, 1-35, 2003.

Huth, R., Pokorná, L., Bochníček, J., and Hejda, P.: Combined solar and QBO effects on the modes of low-frequency atmospheric variability in the Northern Hemisphere, Journal of Atmospheric and Solar-Terrestrial Physics, 71(13), 1471-1483, 2009.

Lejenas, H., and Okland, H.: Characteristics of Northern Hemisphere blocking as determined from a long time series of observational data, Tellus , 35A, 350-362, 1983.

Lohmann, G., Rimbu, N., and Dima, M.: Climate signature of solar irradiance variations: analysis of long-term instrumental, historical, and proxy data, International Journal of Climatology, 24(8), pp.1045-1056, 2004. 
Hydrol. Earth Syst. Sci. Discuss., doi:10.5194/hess-2016-304, 2016

Manuscript under review for journal Hydrol. Earth Syst. Sci.

Published: 28 June 2016

(c) Author(s) 2016. CC-BY 3.0 License.

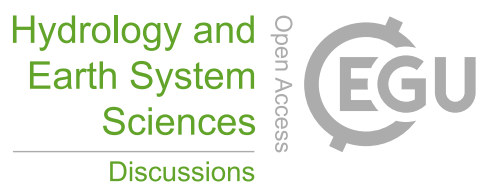

693

694

695

696

697

698

699

700

701

702

703

704

705

706

707

708

709

710

711

712

713

714

715

716

717

718

719

720

721

722

723

724

725

726

727

728

729

730

731

732

733

734

735

736

737

738

739

740

741

Love, J. J., K. Mursula, V. C. Tsai, and Perkins, D. M.: Are secular correlations between sunspots, geomagnetic activity, and global temperature significant?, Geophys. Res. Lett., 38, L21703, doi: 10.1029/2011GL049380, 2011.

Mann, M. E. and Lees, J.: Robust estimation of background noise and signal detection in climatic time series, Climatic Change, 33, 409-445, 1996.

Mann, M. E.: On smoothing potentially non-stationary climate time series, Geophys. Res. Lett., 31, L07214, doi: 10.1029/2004GL019569, 2004.

Mann, M. E.: Smoothing of climate time series revisited, Geophys. Res. Lett., 35, L16708, doi: 10.1029/2008GL034716, 2008.

Mares, I., Mares, C., Mihailescu, M.: NAO impact on the summer moisture variability across Europe, Physics and chemistry of the Earth, 27, 1013-1017, 2002.

Mares C., Mares, I., and Stanciu, A: On the possible causes of the severe drought in the Danube lower basin in 2003, in: Proceedings of the International Conference on "Water Observation and Information System for Decision Support" Ohrid, Republic of Macedonia, 23- 26 May., 2006. http://balwois.mpl.ird.fr/balwois/administration/full_paper/ffp-672.pdf )

Mares, C., Mares, I. and Stanciu, A.: Extreme value analysis in the Danube lower basin discharge time series in the $20^{\text {th }}$ century, Theoretical and Applied Climatology, 95, 223233, 2009.

Mares, I., Mares,C., Stanciu,A., and Mihailescu, M.: On the climate models performances to simulate the main predictors that influence the discharges in the Danube middle and lower basin, Geophysical Research Abstracts, 13, EGU2011-2325, EGU General Assembly, 2011.

Mares, C., Mares,I. Stanciu, A., and Mihailescu,M.: North Atlantic Oscillation (NAO) influence on the Danube lower basin, Proc. Fifth Int. Scientific Conf. on Water, Climate and Environment:BALWOIS 2012, Ohrid, Macedonia, Balwois, 2012-771, 2012.

Mares, I., Mareş, C. and Mihăilescu M.: On the statistical significance of the sea level pressure climatic signal simulated by general circulation models for the 21 st century over Europe. Rev. Roum. Géophysique, 25-40, $2013 \mathrm{a}$.

Mares, I., Mareş, C., and Mihailescu, M.: Stochastic modeling of the connection between sea level pressure and discharge in the Danube lower basin by means of Hidden Markov Model, EGU General Assembly Conference Abstracts, 15, 7606, 2013b.

Mares, I., Dobrica, V., Demetrescu, C. and Mares,C.: Moisture variability in the Danube lower basin: an analysis based on the Palmer drought indices and the solar/geomagnetic activity influence, Geophysical Research Abstracts, 16, EGU2014-6390, 2014.

Mares, C., Adler M. J., Mares I, Chelcea, S., Branescu, E.: Discharge variability in Romania using Palmer indices and a simple atmospheric index of large-scale circulation, Hydrological Sciences Journal, doi: 10.1080/02626667.2015.1006233), 2015a.

Mares, I., Dobrica,V., Demetrescu, C., and Mares, C.: Influence of the atmospheric blocking on the hydrometeorological variables from the Danube basin and possible response to the solar/geomagnetic activity, Geophysical Research Abstracts, 17, EGU2015-4154-3,2015, EGU General Assembly 2015 (PICO2.6), 2015b.

Mares, C., Mares,I., and Mihailescu, M.: Identification of extreme events using drought indices and their impact on the Danube lower basin discharge, Hydrological Processes, doi: 10.1002/hyp.10895), 2016a.

Mares, I., Dobrica, V. Demetrescu, C., and Mares, C.,: Hydrological response in the Danube lower basin to some internal and external forcing factors of the climate system, Geophysical Research Abstracts, 18, EGU2016-7474, EGU General Assembly 2016b. 
Hydrol. Earth Syst. Sci. Discuss., doi:10.5194/hess-2016-304, 2016

Manuscript under review for journal Hydrol. Earth Syst. Sci.

Published: 28 June 2016

(c) Author(s) 2016. CC-BY 3.0 License.

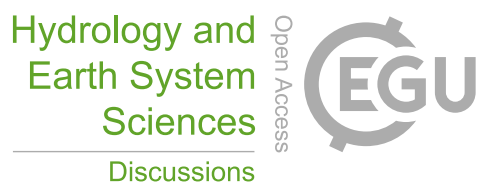

Massei, N., Laignel, B., Deloffre, J., Mesquita, J., Motelay, A., Lafite, R., and Durand, A.: Long-term hydrological changes of the Seine River flow (France) and their relation to the North Atlantic Oscillation over the period 1950-2008, International journal of Climatology, 30(14), pp.2146-2154, 2010.

Palamara, D.R. and Bryant, E.A.: March. Geomagnetic activity forcing of the Northern Annular Mode via the stratosphere, in: Annales Geophysicae, 22, No. 3, 725-731, 2004

Papadimitriou, L. V., Koutroulis, A. G., Grillakis, M. G., and Tsanis, I. K.: High-end climate change impact on European runoff and low flows - exploring the effects of forcing biases, Hydrol, Earth Syst. Sci., 20, 1785-1808, doi:10.5194/hess-20-1785-2016, 2016.

Press, W. H., S. A. Teukolsky, W. T. Vetterling, and Flannery, B. P.: Numerical Recipes, Cambridge Univ. Press, Cambridge, U. K., 1992

Prestes, A., Rigozo, N. R., Nordemann, D. J. R., Wrasse, C. M., Echer, M. S., Echer, E., ... and Rampelotto, P. H.: Sun-earth relationship inferred by tree growth rings in conifers from Severiano De Almeida, Southern Brazil, Journal of Atmospheric and SolarTerrestrial Physics, 73(11), 1587-1593, 2011.

Rimbu N, Boroneanţ C, Buţă C, and Dima M.: Decadal variability of the Danube river flow in the lower basin and its relation with the North Atlantic Oscillation, International Journal of Climatology., 22(10):1169-79, 2002.

Rimbu, N., and Lohmann, G.: Winter and summer blocking variability in the North Atlantic region-evidence from long-term observational and proxy data from southwestern Greenland, Climate of the Past, 7(2), 543-555, 2011.

Rimbu, N., Dima, M., Lohmann, G. and Musat, I.: Seasonal prediction of Danube flow variability based on stable teleconnection with sea surface temperature, Geophysical Research Letters, 32(21), 2005.

Scaife, A. A., Ineson, S., Knight, J. R., Gray, L.J., Kodera, K., and Smith, D. M.: A mechanism for lagged North Atlantic climate response to solar variabilit, Geophys. Res. Letts., 40, 434-439, doi:10.1002/grl.50099, 2013.

Sfîcă, L., Voiculescu, M., and Huth, R.: The influence of solar activity on action centres of atmospheric circulation in North Atlantic, Ann. Geophys., 33, 207-215, doi:10.5194/angeo-33-207-2015, 2015.

Thiebaux, H. J., and Zwiers, F. W.: The interpretation and estimation of effective sample size, J. Climate Appl. Meteor., 23, 800-811, 1984.

Thomson, D. J.: Spectrum estimation and harmonic analysis, IEEE Proc.,70, 1055-1096, 1982.

Torrence, C., and Compo, G. P.: A practical guide to wavelet analysis. Bull. Amer. Meteor. Soc., 79, 61-78, 1998.

Trenberth, K. E., and Paolino, D. A.: The Northern Hemisphere sea level pressure data set: Trends, errors, and discontinuities, Mon. Weather Rev. 108: 855-872, 1980.

Turki, I., Laignel, B., Massei, N., Nouaceur, Z., Benhamiche, N., and Madani, K.: Hydrological variability of the Soummam watershed (Northeastern Algeria) and the possible links to climate fluctuations, Arabian Journal of Geosciences, 9(6), 1-12, 2016.

Valty, P., De Viron, O., Panet, I., and Collilieux, X.,: Impact of the North Atlantic Oscillation on Southern Europe Water Distribution: Insights from Geodetic Data. Earth Interactions, 19(10), 1-16, 2015.

Van Loon H. and Labitzke, K: Association between the 11-Year Solar Cycle, the QBO, and the Atmosphere. Part II: Surface and $700 \mathrm{mb}$ in the Northern Hemisphere in Winter, J. Climate, 1, 905-920, 1988.

Van Loon, H., and Meehl, G. A.: Interactions between externally forced climate signals from sunspot peaks and the internally generated Pacific Decadal and North Atlantic Oscillations, Geophys.Res. Lett., 41, 161-166, doi:10.1002/ 2013GL058670, 2014. 
Hydrol. Earth Syst. Sci. Discuss., doi:10.5194/hess-2016-304, 2016

801

802

803

804

805

806

807

808

809

810

811

812

813

814

815

Von Storch H.V. and Zwiers F. W.: Statistical Analysis in Climate Research. Cambridge University Press, 484, 1999.

Wang, J. S., and Zhao, L.: Statistical tests for a correlation between decadal variation in June precipitation in China and sunspot number, J. Geophys. Res., 117, D23117, doi:10.1029/2012JD018074, 2012.

Zanchettin, D., Rubino, A., Traverso, P., and Tomasino, M. : Impact of variations in solar activity on hydrological decadal patterns in northern Italy, J. Geophys. Res., 113, D12102, doi: 10.1029/2007JD009157, 2008.

Zwiers, F. W., and von Storch H: Taking Serial Correlation into Account in Tests of the Mean. J. Climate, 8, 336_351, 1995

Table 1. Correlation coefficient between first principal component (PC1)

for the precipitation and atmospheric indices NAO and GBO, during winter

\begin{tabular}{|c|c|c|}
\hline Period & NAOI & GBOI \\
\hline $1916-1957$ & -0.36 & $\mathbf{0 . 7 5}$ \\
\hline $1958-1999$ & $\mathbf{- 0 . 4 3}$ & $\mathbf{0 . 8 4}$ \\
\hline
\end{tabular}

Table 2. Simultaneous correlation (1901-2000) with confidence level (CL) at least 95\%, for unfiltered (UF) data, terrestrial variables filtered by low pass filter (LPF) and both time series correlated, smoothed by band pass filtered and the band is specified in the braketes. $r$-Pearson correlation coefficient, $t$ - the values of test $t, \tau$ - Kendall correlation coefficient, $\mathrm{p}$ - significance $\mathrm{p}$-level, $N_{\text {eff }}$ is the effective number.

\begin{tabular}{|c|c|c|c|c|c|c|c|}
\hline Variable & Season & $r$ & $t$ & $\tau$ & $p$ & $N_{\text {eff }}$ & $C L$ \\
\hline \multicolumn{8}{|c|}{ Correlation with aa } \\
\hline PC1_TT(UF) & Spring & 0.224 & 2.184 & 0.137 & 0.043 & 92 & $95 \%$ \\
\hline PC1_TT(4-8) & Spring & 0.606 & 6.457 & 0.401 & 0.000 & 74 & $99.5 \%$ \\
\hline PC1_TT(UF) & Summer & 0.310 & 2.663 & 0,206 & 0.002 & 69 & $99 \%$ \\
\hline PC1_TT(LPF) & Summer & 0.345 & 2.037 & 0.210 & 0.002 & 33 & $95 \%$ \\
\hline PC1_TT(9-15) & Summer & 0.796 & 5.130 & 0.570 & 0.000 & 17 & $99.5 \%$ \\
\hline PC1_TT(LPF) & Fall & 0.453 & 2.865 & 0.304 & 0.000 & 34 & $99 \%$ \\
\hline PC1_PP(LPF) & Spring & -0.371 & 2.201 & -0.315 & 0.000 & 32 & $95 \%$ \\
\hline PC1_PP(9-15) & Spring & -0.669 & 3.437 & -0.501 & 0.000 & 17 & $99.5 \%$ \\
\hline PC1_PP(9-15) & Summer & -0.721 & 3.910 & -0.523 & 0.000 & 16 & $99.5 \%$ \\
\hline TPPI(LPF) & Fall & 0.452 & 2.869 & 0.310 & 0.000 & 34 & $99 \%$ \\
\hline TPPI(UF) & Spring & 0.275 & 2.676 & 0.186 & 0.006 & 90 & $99 \%$ \\
\hline TPPI(LPF) & Spring & 0.299 & 1.736 & 0.261 & 0.000 & 33 & $90 \%$ \\
\hline TPPI(4-8) & Spring & 0.525 & 5.313 & 0.338 & 0.000 & 76 & $99.5 \%$ \\
\hline TPPI(9-15) & Spring & 0.402 & 1.660 & 0.325 & 0.000 & 16 & $85-90 \%$ \\
\hline TPPI(UF) & Summer & 0.224 & 2.121 & 0.153 & 0.025 & 87 & $95 \%$ \\
\hline TPPI(LPF) & Summer & 0.318 & 1.921 & 0.187 & 0.006 & 35 & $\sim 95 \%$ \\
\hline TPPI(9-15) & Summer & 0.787 & 4.856 & 0.572 & 0.000 & 16 & $99.5 \%$ \\
\hline Q_ORS(LPF) & Fall & -0.324 & 1.946 & -0.210 & 0.002 & 34 & $\sim 95 \%$ \\
\hline Q_ORS(9-15) & Fall & -0.562 & 2.454 & -0.419 & 0.000 & 15 & $95-98 \%$ \\
\hline Q_ORS(9-15) & Summer & -0.656 & 3.210 & -0.470 & 0.000 & 16 & $99 \%$ \\
\hline & & & & & & & \\
\hline
\end{tabular}


Hydrol. Earth Syst. Sci. Discuss., doi:10.5194/hess-2016-304, 2016

Manuscript under review for journal Hydrol. Earth Syst. Sci.

816

817

818

819

820

821

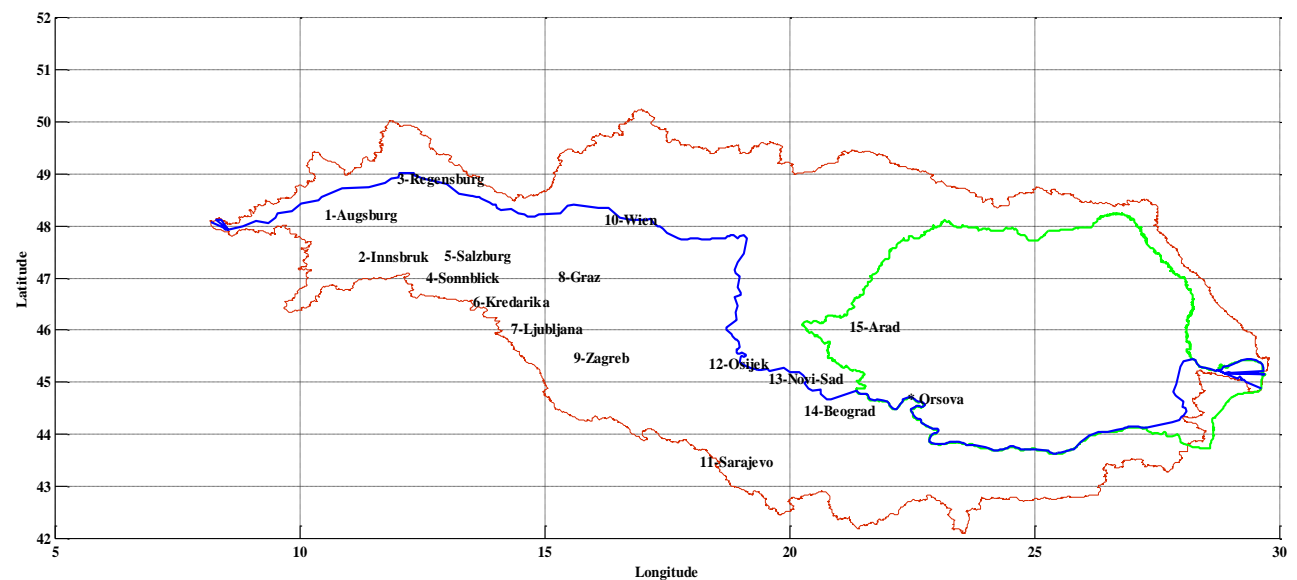

Table 3. Same as Table 2 but for 53 years (1948-2000).

\begin{tabular}{|c|c|c|c|c|c|c|r|}
\hline Variable & Season & $r$ & $t$ & $\tau$ & $p$ & $N_{\text {eff }}$ & \multicolumn{2}{c|}{$C L$} \\
\hline \multicolumn{7}{|c|}{ Correlation with aa } \\
\hline EBI (UF) & Spring & $\mathbf{0 . 2 5 9}$ & $\mathbf{1 . 8 3 6}$ & $\mathbf{0 . 1 5 1}$ & $\mathbf{0 . 1 1 0}$ & $\mathbf{4 9}$ & $\sim 95 \%$ \\
\hline EBI (4-8) & Spring & $\mathbf{0 . 5 2 8}$ & $\mathbf{3 . 8 6 4}$ & $\mathbf{0 . 3 8 2}$ & $\mathbf{0 . 0 0 0}$ & $\mathbf{4 1}$ & $>\mathbf{9 9 \%}$ \\
\hline $\mathrm{ABI}(\mathrm{UF})$ & Fall & -0.257 & 1.848 & -0.118 & 0.210 & 51 & $\sim 95 \%$ \\
\hline $\mathrm{ABI}(9-15)$ & Spring & 0.605 & 2.157 & 0.426 & 0.000 & 10 & $>95 \%$ \\
\hline $\mathrm{AEBI}(9-15)$ & Winter & 0.749 & 3.134 & 0.589 & 0.000 & 10 & $98.5 \%$ \\
\hline \multicolumn{7}{|c|}{ Correlation with flux 10.7 cm } \\
\hline TPPI(LPF) & Spring & 0.444 & 1.502 & 0.322 & 0.001 & 11 & $85-90 \%$ \\
\hline ABI(4-8) & Fall & 0.578 & 4.124 & 0.312 & 0.001 & 36 & $99.9 \%$ \\
\hline AEBI(4-8) & Fall & 0.530 & 3.697 & 0.360 & 0.000 & 37 & $99.9 \%$ \\
\hline EBI (4-8) & Winter & $\mathbf{0 . 4 1 9}$ & $\mathbf{2 . 6 7 8}$ & $\mathbf{0 . 2 7 2}$ & $\mathbf{0 . 0 0 4}$ & $\mathbf{3 7}$ & $\mathbf{9 8 . 5 \%}$ \\
\hline Q_ORS(4-8) & Winter & $\mathbf{- 0 . 6 0 3}$ & $\mathbf{4 . 3 9 0}$ & $\mathbf{- 0 . 3 5 1}$ & $\mathbf{0 . 0 0 0}$ & $\mathbf{3 6}$ & $\mathbf{9 9 . 9 \%}$ \\
\hline GBOI (4-8) & Winter & $\mathbf{- 0 . 6 9 5}$ & $\mathbf{6 . 0 3 4}$ & $\mathbf{- 0 . 4 2 8}$ & $\mathbf{0 . 0 0 0}$ & $\mathbf{4 1}$ & $\mathbf{9 9 . 9 \%}$ \\
\hline
\end{tabular}
1

\begin{tabular}{|c|c|c|c|c|c|c|c|}
\hline \multicolumn{7}{|c|}{ Correlation with Wolf number } \\
\hline PC1_TT(4-8) & Summer & 0.288 & 2.453 & 0.157 & 0.021 & 68 & $98 \%$ \\
\hline PC1_TT(9-15) & Fall & 0.699 & 3.770 & 0.550 & 0.000 & 17 & $99.5 \%$ \\
\hline PC1_PP(4-8) & Spring & $\mathbf{- 0 . 2 4 2}$ & $\mathbf{2 . 1 3 3}$ & $\mathbf{- 0 . 1 9 0}$ & $\mathbf{0 . 0 0 5}$ & $\mathbf{7 5}$ & $\mathbf{9 5 - 9 8 \%}$ \\
\hline PC1_PP(9-15) & Spring & $-\mathbf{- 0 . 5 3 8}$ & $\mathbf{2 . 4 1 7}$ & $\mathbf{- 0 . 3 6 3}$ & $\mathbf{0 . 0 0 0}$ & $\mathbf{1 6}$ & $\mathbf{9 5 - 9 8 \%}$ \\
\hline PC1_PP(4-8) & Winter & -0.370 & 3.298 & -0.265 & 0.000 & 70 & $>99 \%$ \\
\hline TPPI(UF) & Spring & $\mathbf{0 . 2 1 1}$ & 1.973 & $\mathbf{0 . 1 4 8}$ & $\mathbf{0 . 0 2 9}$ & $\mathbf{8 5}$ & $\mathbf{9 5 \%}$ \\
\hline TPPI(LPF) & Spring & $\mathbf{0 . 2 9 9}$ & $\mathbf{1 . 7 3 6}$ & $\mathbf{0 . 2 6 1}$ & $\mathbf{0 . 0 0 0}$ & $\mathbf{3 3}$ & $\mathbf{9 0 \%}$ \\
\hline TPPI(4-8) & Spring & $\mathbf{0 . 2 4 5}$ & $\mathbf{2 . 1 5 4}$ & $\mathbf{0 . 1 5 9}$ & $\mathbf{0 . 0 1 9}$ & $\mathbf{7 4}$ & $\mathbf{9 5 - 9 8 \%}$ \\
\hline TPPI(9-15) & Spring & $\mathbf{0 . 5 8 5}$ & $\mathbf{2 . 7 0 8}$ & $\mathbf{0 . 3 9 5}$ & $\mathbf{0 . 0 0 0}$ & $\mathbf{1 6}$ & $\mathbf{9 8 \%}$ \\
\hline TPPI(9-15) & Fall & 0.673 & 3.796 & 0.553 & 0.000 & 19 & $99 \%$ \\
\hline GBOI (4-8) & Summer & -0.346 & 2.982 & -0.230 & 0.001 & 67 & $99.5 \%$ \\
\hline GBOI (4-8) & Winter & -0.343 & 3.169 & -0.218 & 0.001 & 77 & $>99 \%$ \\
\hline GBOI (17-28) & Fall & -0.899 & 3.485 & -0.707 & 0.000 & 5 & $95-98 \%$ \\
\hline Q_ORS (4-8) & Winter & -0.263 & 2.329 & -0.163 & 0.016 & 75 & $98 \%$ \\
\hline
\end{tabular}


Hydrol. Earth Syst. Sci. Discuss., doi:10.5194/hess-2016-304, 2016

Manuscript under review for journal Hydrol. Earth Syst. Sci.

Published: 28 June 2016

(c) Author(s) 2016. CC-BY 3.0 License.
Hydrology and

Earth System

Sciences

Discussions

(c) (i)

19

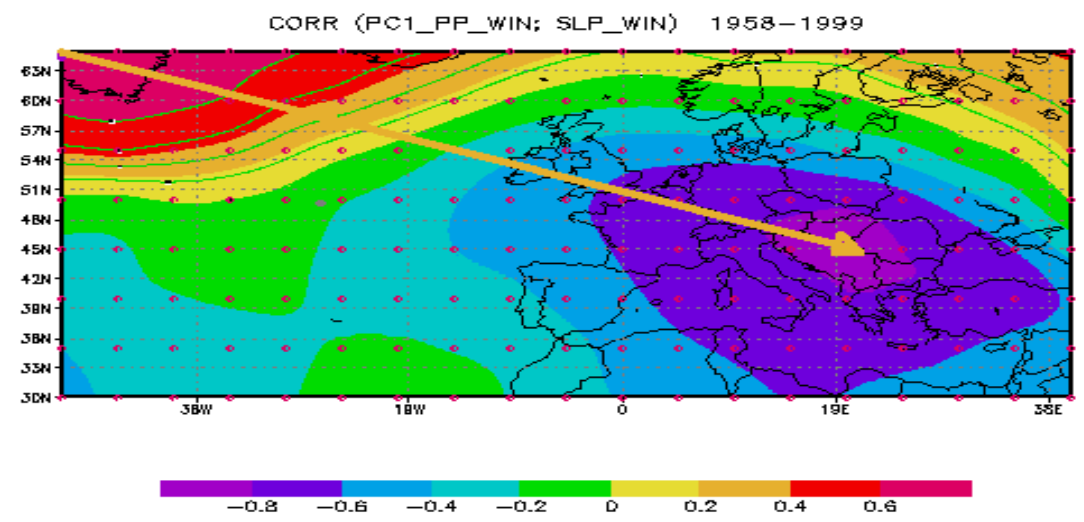

Figure 2. Spatial distribution of correlation coefficients between SLP NCAR and observed PC1- PP during winter for 1958-1999.

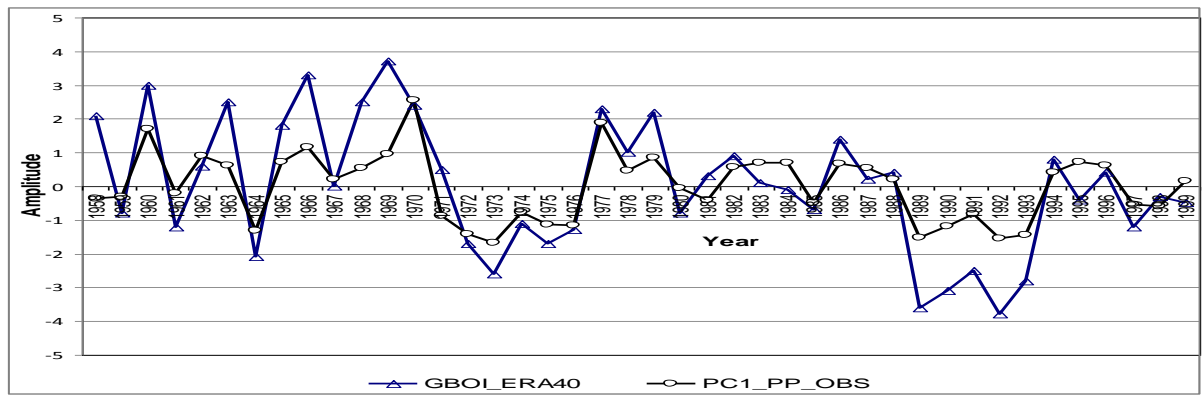

Figure 3. Winter precipitation PC1 versus winter GBOI for 1958-1999 (R=0.84).

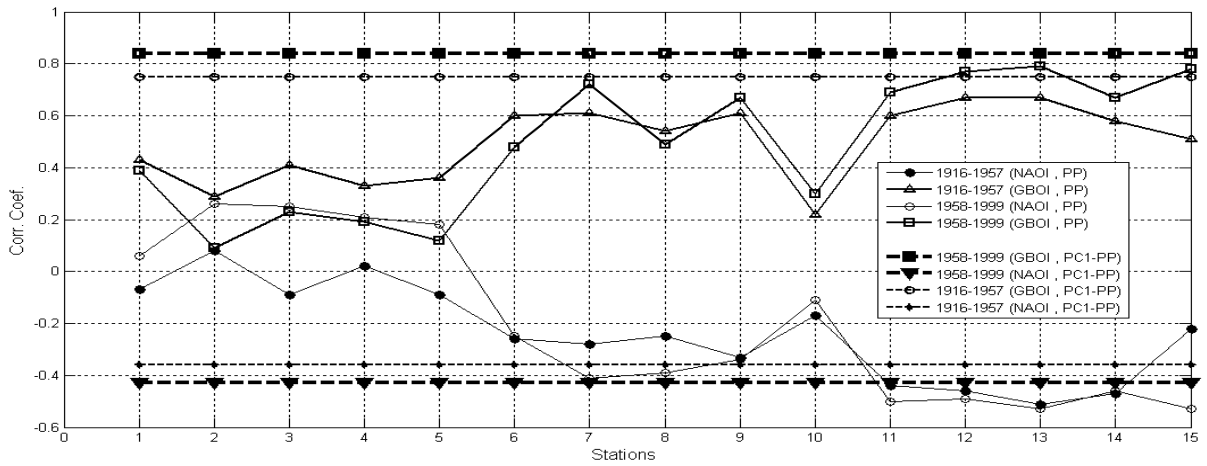

Figure 4. Correlation coefficients between winter precipitation at 15 stations and NAOI and GBOI for two periods: a) 1916-1957; b) 1958-1999. The correlations between PC1-PP and two indices are marked by horizontal lines. 
Hydrol. Earth Syst. Sci. Discuss., doi:10.5194/hess-2016-304, 2016

Manuscript under review for journal Hydrol. Earth Syst. Sci.

Published: 28 June 2016

(c) Author(s) 2016. CC-BY 3.0 License.
Hydrology and

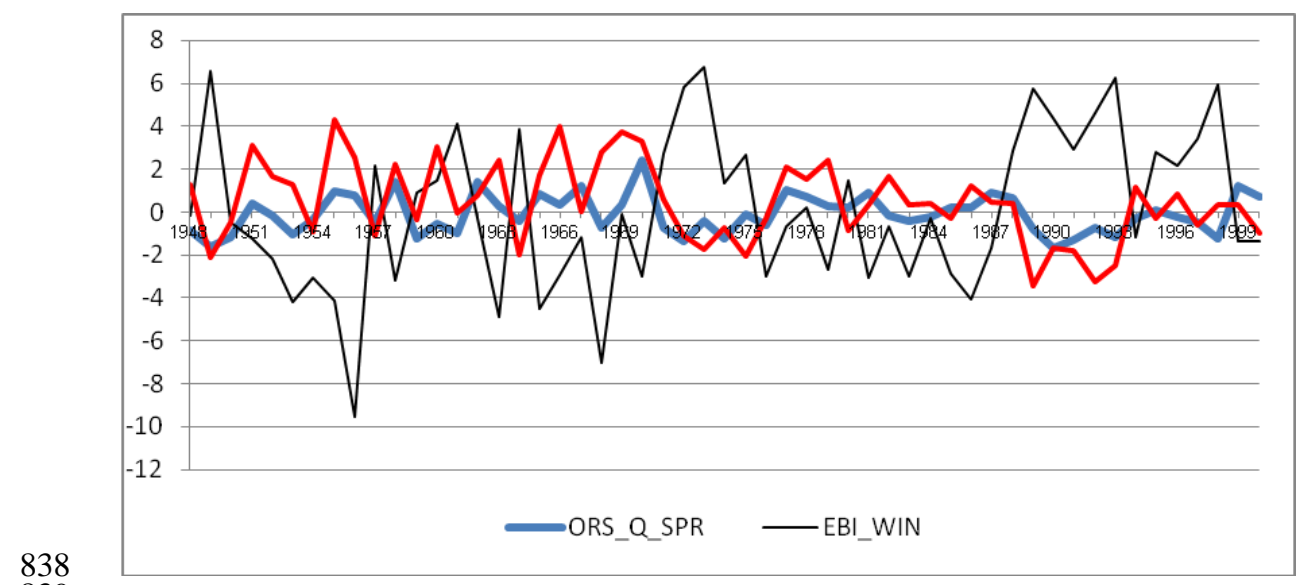

Figure 5. Spring Orsova discharge versus winter European blocking index $(R=-0.54)$

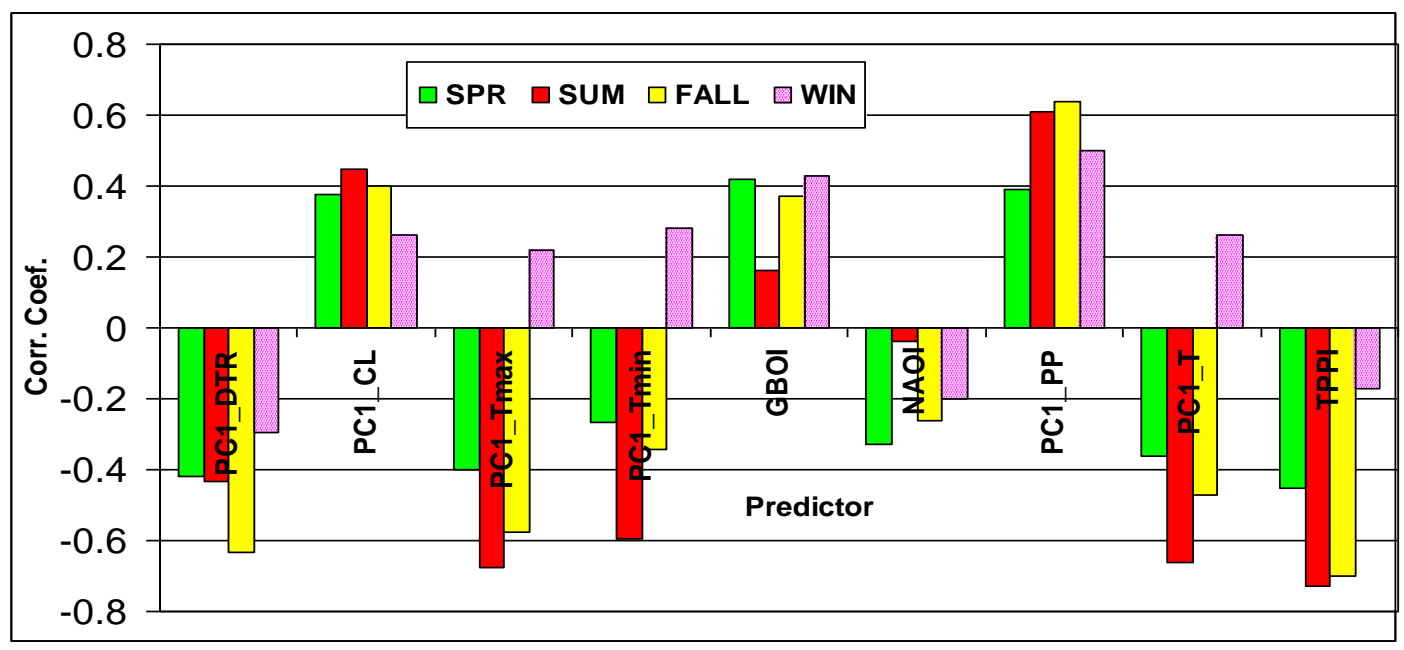

Figure 6. Simultaneous correlations between Danube discharge at Orsova and nine predictors (1901-2000) 
Hydrol. Earth Syst. Sci. Discuss., doi:10.5194/hess-2016-304, 2016

Manuscript under review for journal Hydrol. Earth Syst. Sci.

Published: 28 June 2016

856

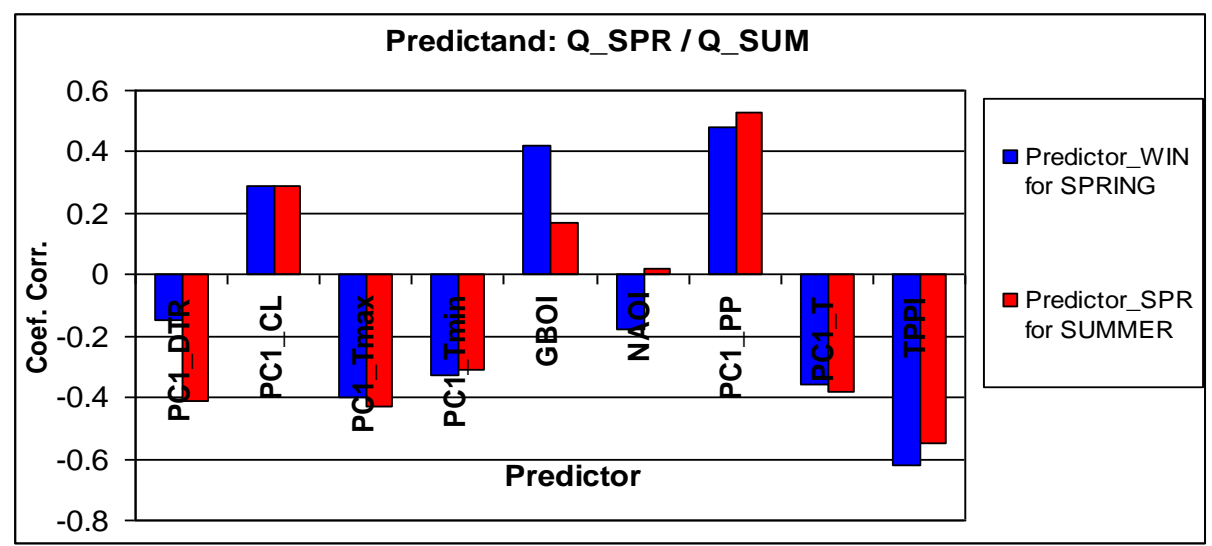

Figure 7. The correlation between Orsova discharge (Q) in the spring / summer and the nine predictors in the winter/spring.

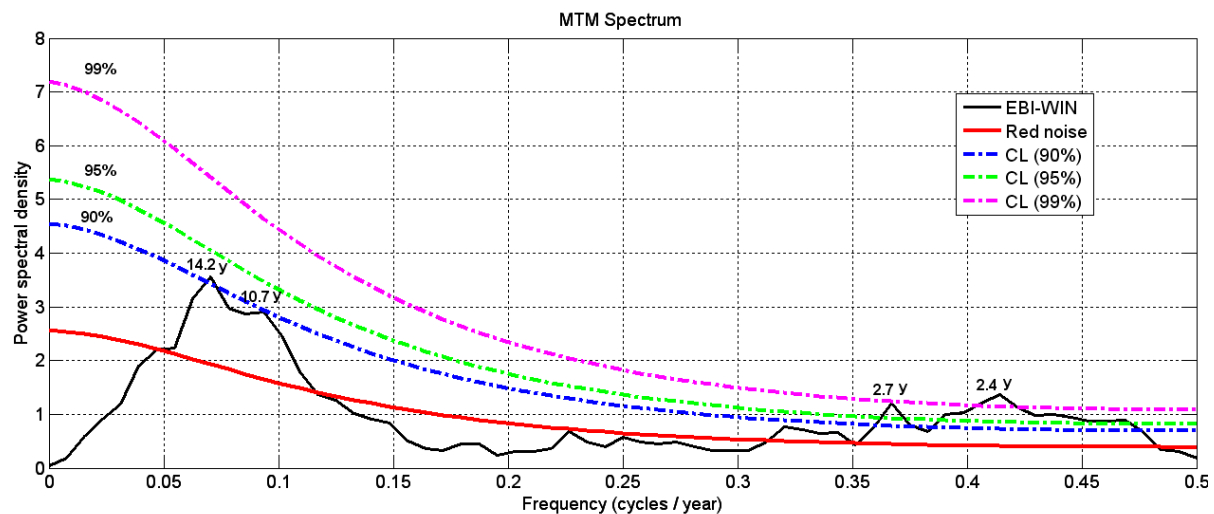

a)

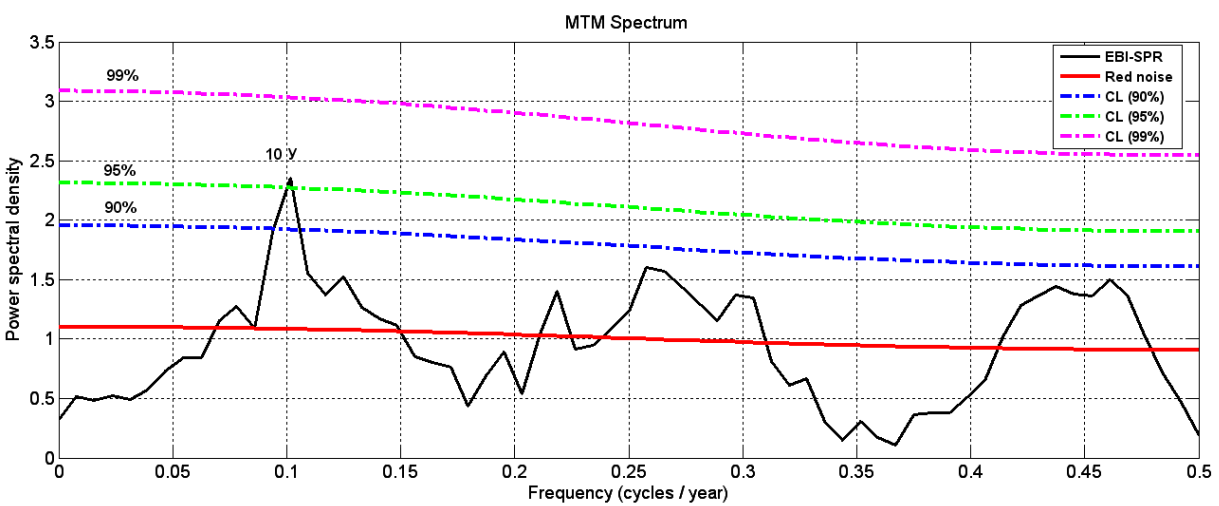

b) 
Hydrol. Earth Syst. Sci. Discuss., doi:10.5194/hess-2016-304, 2016

Manuscript under review for journal Hydrol. Earth Syst. Sci.

Published: 28 June 2016

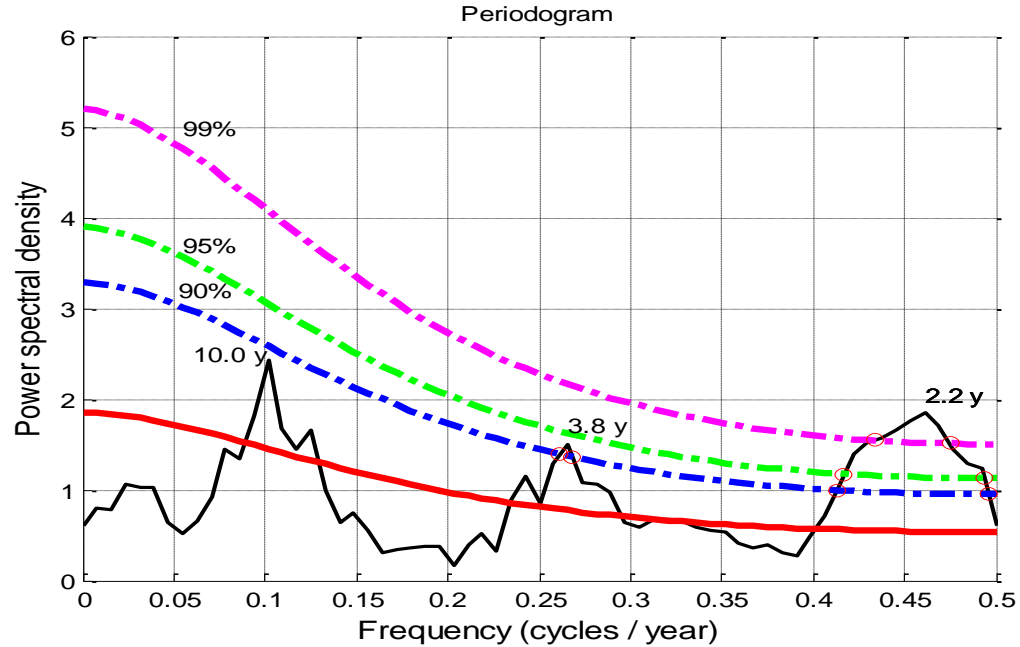

c)

Figure 8. Power spectra for the blocking indices: winter EBI (a), spring EBI (b) and spring AEBI (c).

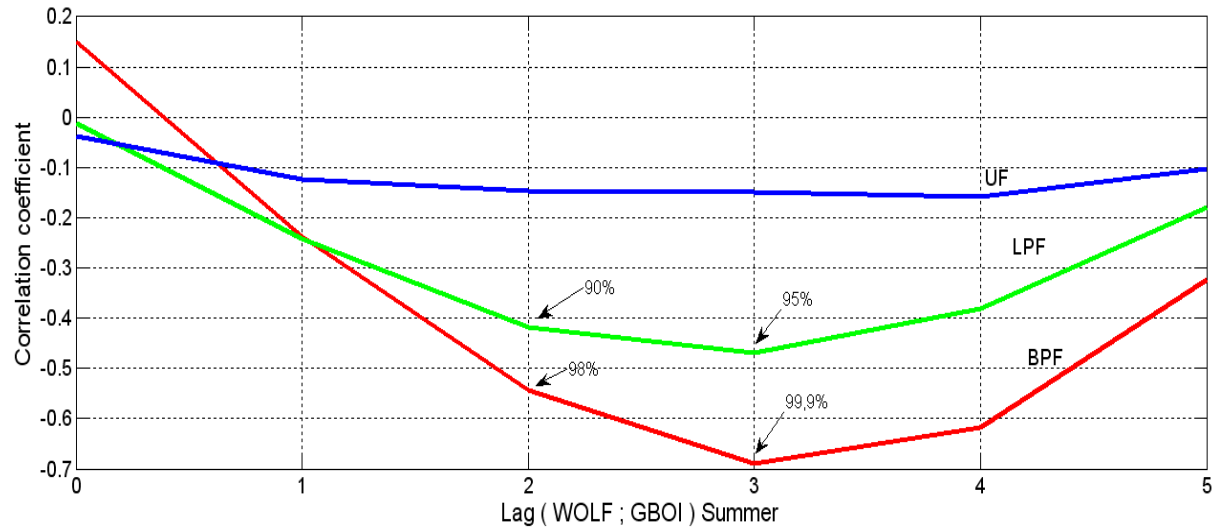

Figure 9. Correlation coefficients, between Wolf number and GBOI index in summer with the lags $0-5$, for three time series: unfiltered (UF), smoothing by low pass filter (LPF) and by band pass filter (9-15) 
Hydrol. Earth Syst. Sci. Discuss., doi:10.5194/hess-2016-304, 2016

Manuscript under review for journal Hydrol. Earth Syst. Sci.

Published: 28 June 2016

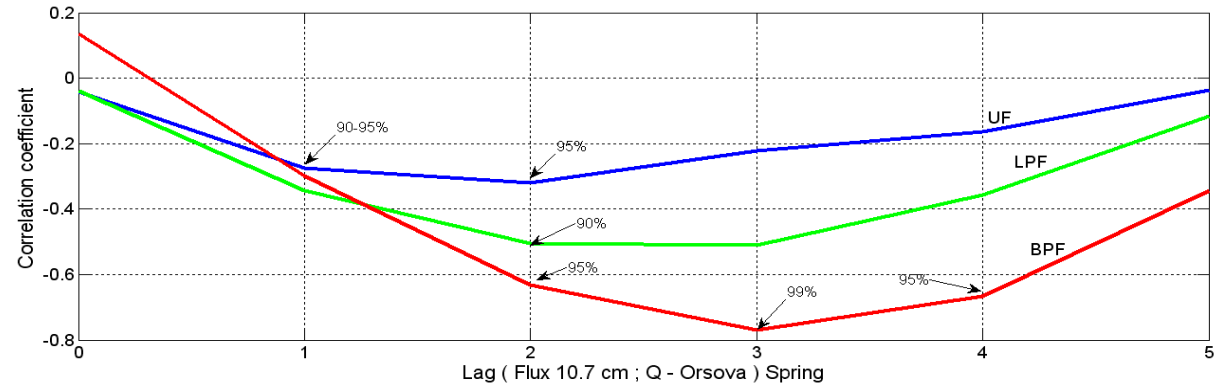

a)

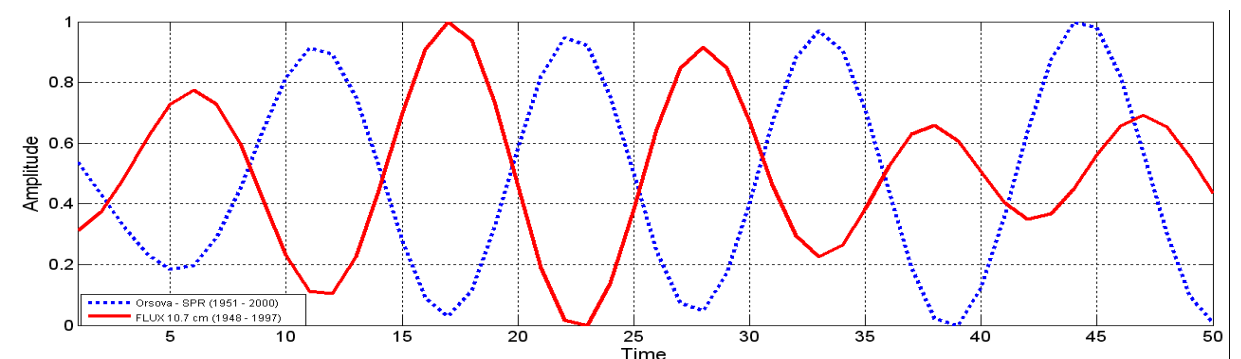

b)

Figure 10. Solar (Flux 10.7cm) signal in the Orsova dischage (Q_ORS), during spring (1948-2000).

a) Correlation coefficients, between solar flux and Orsova discharge with the lags $0-5$, for three time series: unfiltered (UF), smoothing by low pass filter (LPF) and by band pass filter (9-15);

b) Temporal behavior of the solar flux and Q_ORS, filtered (9-15) with a delay of 3 years to flux. The time series are normalized.

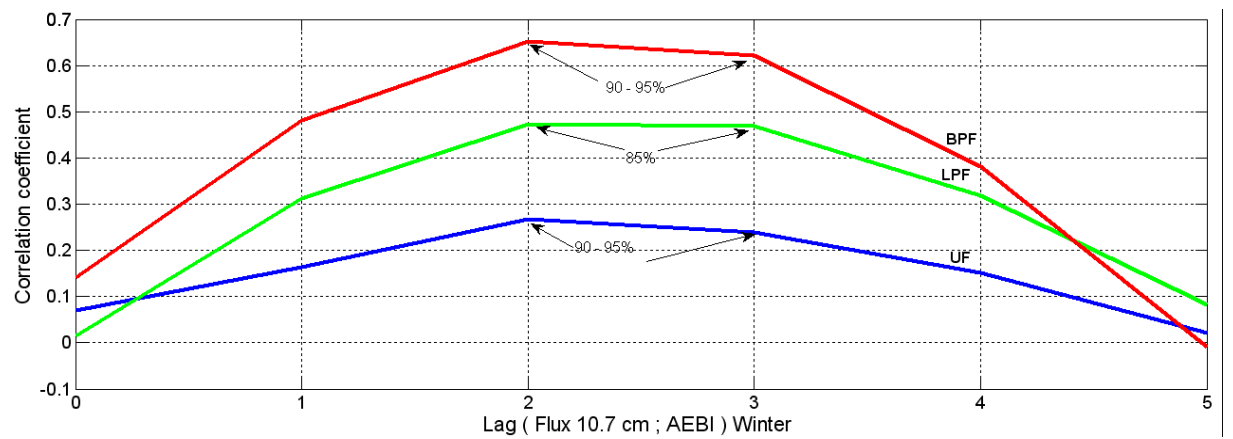

Figure 11. Correlation coefficients, between solar flux and AEBI with the lags 0-5, during winter (1948-2000), for three time series: unfiltered (UF), smoothing by low pass filter (LPF) and by band pass filter (9-15). 
Hydrol. Earth Syst. Sci. Discuss., doi:10.5194/hess-2016-304, 2016

Manuscript under review for journal Hydrol. Earth Syst. Sci.

Published: 28 June 2016

909

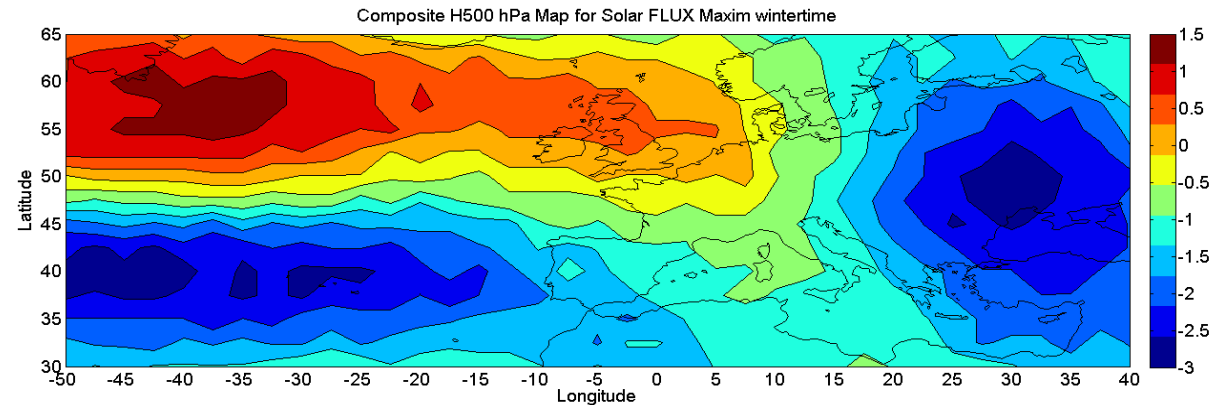

912

a)

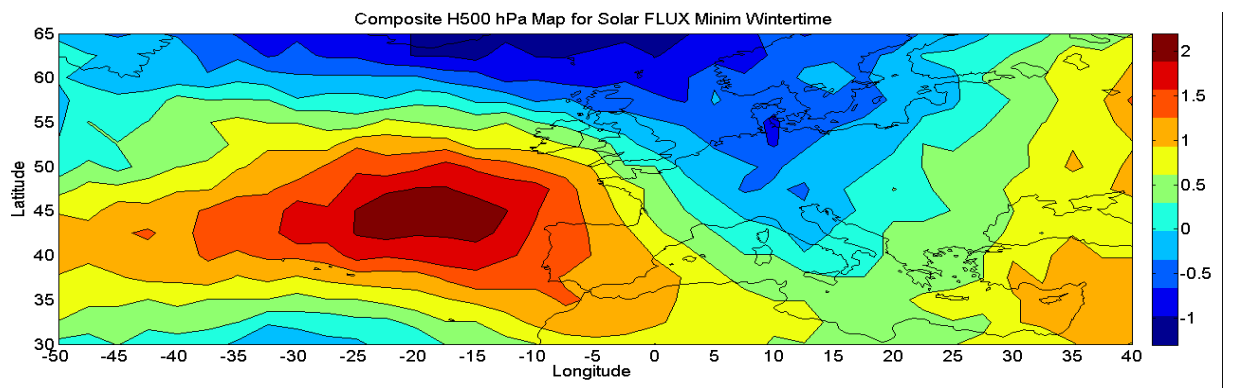

b)

Figure 12. Composite maps for the winter $\mathrm{H} 500 \mathrm{hPa}$ anomalies, corresponding to solar flux associated 